\title{
Oligodendrocyte myelin glycoprotein as a novel target for pathogenic autoimmunity in the CNS
}

Ramona Gerhards ${ }^{1}$ (D, Lena Kristina Pfeffer ${ }^{1}$, Jessica Lorenz ${ }^{1}$, Laura Starost ${ }^{2}$, Luise Nowack² , Franziska S. Thaler ${ }^{1}$, Miriam Schlüter ${ }^{1}$, Heike Rübsamen ${ }^{1}$, Caterina Macrini ${ }^{1}$, Stephan Winklmeier ${ }^{1}$, Simone Mader ${ }^{1}$, Mattias Bronge ${ }^{3}$, Hans Grönlund ${ }^{3}$, Regina Feederle ${ }^{4}$, Hung-En Hsia ${ }^{5}$, Stefan F. Lichtenthaler ${ }^{5,11}$, Juliane Merl-Pham ${ }^{6}$, Stefanie M. Hauck ${ }^{6}$, Tanja Kuhlmann², Isabel J. Bauer ${ }^{1}$, Eduardo Beltran ${ }^{1}$, Lisa Ann Gerdes ${ }^{1}$, Aleksandra Mezydlo ${ }^{1}$, Amit Bar-Or ${ }^{7}$, Brenda Banwell ${ }^{8}$, Mohsen Khademi ${ }^{9}$, Tomas Olsson ${ }^{9}$, Reinhard Hohlfeld ${ }^{1,11}$, Hans Lassmann ${ }^{10}$, Tania Kümpfel ${ }^{1}$, Naoto Kawakami ${ }^{1+}$ and Edgar Meinl ${ }^{1 *}$ (])

\begin{abstract}
Autoimmune disorders of the central nervous system (CNS) comprise a broad spectrum of clinical entities. The stratification of patients based on the recognized autoantigen is of great importance for therapy optimization and for concepts of pathogenicity, but for most of these patients, the actual target of their autoimmune response is unknown. Here we investigated oligodendrocyte myelin glycoprotein (OMGP) as autoimmune target, because OMGP is expressed specifically in the CNS and there on oligodendrocytes and neurons. Using a stringent cell-based assay, we detected autoantibodies to OMGP in serum of $8 / 352$ patients with multiple sclerosis, 1/28 children with acute disseminated encephalomyelitis and unexpectedly, also in one patient with psychosis, but in none of 114 healthy controls. Since OMGP is GPI-anchored, we validated its recognition also in GPI-anchored form. The autoantibodies to OMGP were largely lgG1 with a contribution of lgG4, indicating cognate T cell help. We found high levels of soluble OMGP in human spinal fluid, presumably due to shedding of the GPI-linked OMGP. Analyzing the pathogenic relevance of autoimmunity to OMGP in an animal model, we found that OMGP-specific T cells induce a novel type of experimental autoimmune encephalomyelitis dominated by meningitis above the cortical convexities. This unusual localization may be directed by intrathecal uptake and presentation of OMGP by meningeal phagocytes. Together, OMGP-directed autoimmunity provides a new element of heterogeneity, helping to improve the stratification of patients for diagnostic and therapeutic purposes.
\end{abstract}

Keywords: Autoantigen, Multiple sclerosis, Neuroinflammation, Autoimmunity

*Correspondence: edgar.meinl@med.uni-muenchen.de

${ }^{\dagger}$ Naoto Kawakami and Edgar Meinl contributed equally to this work

${ }^{1}$ Institute of Clinical Neuroimmunology, Biomedical Center and University

Hospitals, Ludwig-Maximilians-Universität München, Großhaderner Str. 9, 82152 Planegg-Martinsried, Germany

Full list of author information is available at the end of the article

\section{Introduction}

Inflammatory diseases of the CNS comprise a broad spectrum of disorders, multiple sclerosis is the most abundant one. A misguided immune response to autoantigens expressed in the CNS is expected to drive the disease in these patients $[21,51,52,68]$ and multiple targets of the autoimmune response have been suggested $[8,10$, $15,26,28,29,32,36,42,58,62,70]$. The identification 
of autoantibodies to myelin oligodendrocyte glycoprotein (MOG) [53] and aquaporin-4 (AQP4) [39] in patients with clinical features similar to MS, have eventually resulted in the definition of separate diseases with important therapeutic consequences [44, 60,61], but for most of the patients with inflammatory disorders of the CNS, the target of their autoimmune response has not been identified.

This study analyzes autoimmunity to oligodendrocyte myelin glycoprotein (OMGP), because this protein is specifically expressed in the CNS and there found on both oligodendrocytes and neurons. Therefore, OMGP could provide a target for both white and gray matter pathology. OMGP is a GPI-anchored protein and was originally identified as a $105 \mathrm{kDa}$ glycoprotein of myelin in the CNS [48], which is also expressed by neurons [25]. The most studied function of OMGP is its role as a myelin derived inhibitor of axonal outgrowth [24], by binding to its receptors NgR [76] and PirB [4]. Although an autoimmune response against OMGP had been considered in studies looking at multiple CNS targets $[13,46]$, their abundance in patients has not yet been thoroughly determined and the pathogenic potential of Abs or $\mathrm{T}$ cells directed against OMGP was unknown. We set out to analyze autoantibodies targeting OMGP in patients classified in different disease entities. For the screening, we developed a live cell-based assay (CBA) with membrane anchored OMGP. Thereby, we found Abs to OMGP in $10 / 474$ patients including $2.3 \%$ of patients with MS. Their anti-OMGP reactivity was confirmed with another cell-based system, where OMGP was displayed with its natural GPI anchor. To detect OMGP-specific T cells, we applied a recently developed sensitive method using bead-bound antigen as stimulant [8]. Further, we found that a soluble form of OMGP (sOMGP) is regularly present in the human cerebrospinal fluid (CSF) at high abundance in patients and controls. To gain further insight into the source and presence of OMGP in the CNS, we analyzed cultured oligodendrocytes and neurons from rodents and human oligodendrocytes derived from induced pluripotent stem cells (iPSCs) [17] and proved the presence of OMGP on these cells.

Having detected autoimmunity to OMGP in a subset of patients, we analyzed the pathogenic consequences of autoimmunity to OMGP in an animal model. To this end, we have established a transfer experimental autoimmune encephalomyelitis (EAE) model with OMGP-specific $\mathrm{T}$ cells. This yielded a novel type of EAE characterized by massive lymphocytic meningitis over the brain convexities. For analyzing the pathogenic potential of Abs against OMGP, we generated new monoclonal antibodies (mAbs) to OMGP in rodents. We found that anti-OMGP
Abs, in contrast to anti-MOG mAbs, did not mediate demyelination or other tissue damage in the EAE animal model. These findings might be explained by the large amounts of sOMGP in the CSF: sOMGP might on the one hand block demyelination by anti-OMGP mAbs, while it is constitutively taken up and presented by meningeal phagocytes directing inflammation to the cortical convexities.

Together, this study detects autoimmunity to OMGP in a proportion of patients with CNS inflammation, shows that OMGP-specific $T$ cells mediate a novel type of EAE and provides a mechanistic model for the lesion localization of OMGP-directed autoimmunity.

\section{Materials and methods \\ Cloning of OMGP constructs}

Two OMGP constructs were cloned for cell-based assays into the pEGFP-N1 vector. First, to display OMGP with a membrane anchor (OMGP-TM), the transmembrane spanning part of CD80 (P237-L306, UniProt Q549R2) was placed in between human OMGP (M1-S417, UniProt P23515) and EGFP. Second, to display OMGP with its natural GPI anchor (OMGP-GPI), we used a T2A ribosome-skipping element (GSGEGRGSLLTCGDVEENPGP), which allows to generate two proteins out of one mRNA [14]. To this end, the stop codon of EGFP was deleted in pEGFP-N1, followed by T2A and subsequent complete OMGP sequence, including GPI anchor signal peptide (V418-V440). Rat (UniProt, Q7TQ25) and mouse (UniProt, Q63912) OMGP were cloned similarly, while using the human GPI signal sequence. To obtain OMGP in soluble form, its C-terminal GPI signal sequence was replaced by a linker (GSGMGMGMGMM) plus Avi-tag sequence (GLNDIFEAQKIEWHE), which allows sitespecific enzymatic biotinylation, followed by SGGSG linker and poly-His for IMAC purification, cloned into the PTT5 expression vector.

\section{Cell-based assays to detect antibodies to OMGP}

OMGP-TM, OMGP-GPI (for human, mouse and rat OMGP), and pEGFP-N1 as a control were transiently transfected in HeLa cells. For screening, sera were diluted 1:50 and binding of IgG in serum was detected by FACS as described in detail in the Additional file 1.

\section{Production and purification of recombinant proteins} OMGP and Abs were produced in HEK293-EBNA cells by secretion of proteins into the supernatant. The recombinant mAb specific for OMGP (22H6-hIgG1) was produced with the same human IgG1 Fc-part as the 
anti-MOG specific mAb 8-18C5-hIgG1 [7, 66]. OMGP was enzymatically biotinylated via BirA ligase (Avidity, BirA500).

\section{Generation and characterization of new mAbs to OMGP}

We have developed three new mAbs specific for OMGP, $22 \mathrm{H} 6$ (rat IgG2a/ $\lambda$ ), 31A4 (mouse IgG2b/K) and $14 \mathrm{~A} 9$ (rat IgG2b/ $\lambda$ ) as described in the Additional file 1. These mAbs show strong reactivity to human OMGP in cellbased assays, biotin-streptavidin ELISA and cross react to rodent OMGP. The variable region of $22 \mathrm{H} 6$ was cloned and expressed recombinantly with a human IgG1 Fc part, named 22H6-hIgG1.

\section{Detection of circulating antigen-specific $B$ and $T$ cells}

To detect antigen-specific $T$ cells a recently developed Fluorospot assay was applied [8], as described in the Additional file 1. To detect circulating OMGP-specific $\mathrm{B}$ cells, PBMCs were differentiated to Ab-secreting plasmablasts as described in the Additional file 1. For both assays cryopreserved PBMCs were used. The blood was withdrawn in EDTA tubes. PBMCs were isolated via Pancoll gradient, frozen in FCS with 10\% DMSO in Cool$\mathrm{Cell}^{\mathrm{TM}}$ freezing boxes at $-80{ }^{\circ} \mathrm{C}$ and then transferred to liquid nitrogen.

\section{ELISAs}

Our ELISA detecting Abs to OMGP used recombinantly produced OMGP, which was enzymatically biotinylated on its Avi-tag. Further details and ELISAs to detect MOG-Ab h8-18C5 and to quantify C1q-binding of OMGP-specific Abs are in the Additional file 1. We developed an ELISA to measure soluble OMGP. To this end, we used our new anti-OMGP mAb 14A9 for coating, rat rIgG2b (BD Biosciences, 556968) was the control $\mathrm{Ab}$. For detection, we used the polyclonal OMGP antibody (R\&D, AF1674), which we had biotinylated with a biotinylation kit (abcam, ab201795). To detect OMGP in CSF, samples were diluted 1:30 in PBST-0.5\% BSA.

\section{Western blot detecting soluble OMGP}

CSF samples were pooled and approximately $30 \times$ concentrated using filter columns (Amicon $3 \mathrm{kDa}$ ). These, together with recombinant OMGP and immunoglobulins were separated by SDS gel (Invitrogen, NP0321) and transferred on an activated (10\% methanol) PVDF membrane (GE Healthcare, 10600023). As primary Ab, goat anti-OMGP (R\&D, AF1674) was used. As secondary Ab, donkey anti-goat-IgG-HRP (Invitrogen, A16005) was used, because it shows only minimal cross-reactivity with human IgG due to absorption against human IgG. ECL prime solution (GE Healthcare, RPN2232) was used and signal was detected by digital imaging systems Odyssey Fc from Leica.

Proteomic sample preparation and LC-MSMS measurement $20 \mu \mathrm{l}$ of each CSF sample $(n=20)$ were analyzed by a combination of liquid chromatography with tandem mass spectrometry. Details are described in the Additional file 1 .

\section{Culture and staining of primary cell cultures and spinal cord tissue}

Hippocampi and cortices were taken from embryonic (E16) mice and oligodendrocyte precursor cells prepared from 6 to 9 days old mice. Spinal cord tissue was analyzed as free-floating $55 \mu \mathrm{m}$ thick stainings. Details are described in the Additional file 1.

\section{Affinity purification of patient-derived Abs to OMGP}

Plasma was precipitated by $\mathrm{NH}_{4} \mathrm{SO}_{4}$ reconstituted with PBS supplemented with $1 / 10$ of volume of solubilization buffer $(1.5 \mathrm{M} \mathrm{NaCl}, 60 \mathrm{mM}$ Tris-base, $30 \mathrm{mM}$ Tris- $\mathrm{HCl}, \mathrm{pH} 7.4$ ), which contains freshly added $1 \%$ Octyl- $\beta$-Glucopyranoside. After pre-absorption with a streptavidin column (GE Healthcare 17-5112-01), sample was applied to a streptavidin column loaded with $1 \mathrm{mg}$ biotinylated OMGP, eluted with $0.1 \mathrm{M}$ glycine, $0.15 \mathrm{M} \mathrm{NaCl}$ buffer (pH 3) and directly dropped into $500 \mu \mathrm{l}$ of $1 \mathrm{M}$ Tris solution ( $\mathrm{pH} 8.8)$. Antibodies were concentrated with $50 \mathrm{~K}$ centrifugal filters (Amicon) and dialyzed against PBS.

\section{OMGP-specific T cell lines in the rat EAE model}

To obtain antigen-specific $\mathrm{T}$ cell lines, Lewis rats were immunized with an emulsion of recombinant OMGP protein and complete Freund's adjuvant basically as described previously [66]. This protocol yields preferentially $\mathrm{CD}^{+}{ }^{+} \mathrm{T}$ cell lines. Flow cytometric characterization is described in Additional file 1.

Freshly restimulated $\mathrm{T}$ cells were injected intravenously for EAE induction $\left(10 \times 10^{6}\right.$ OMGP-specific $\mathrm{T}$ cells $/ 15 \times 10^{6}$ OVA-specific $\mathrm{T}$ cells $/ 1.1 \times 10^{6} \mathrm{MBP}$ specific $\mathrm{T}$ cells). Clinical scores and weight of Lewis rats were checked daily. On day two after $\mathrm{T}$ cell transfer, animals were anesthetized by fentanyl/midazolam/medetomidine and $500 \mu \mathrm{g}$ of antibodies were injected intrathecally into the cisterna magna as following: of the anti-OMGP mAbs (31A4, 14A9, 22H6, 22H6-hIgG1), respective isotype controls (mIgG2b, BD Pharmingen, 559530; rIgG2b BD Pharmingen, 556968; rIgG2a BD Pharmingen, 553926), $100 \mu \mathrm{g}$ of anti-OMGP 
MAB1674 or control MAB005, $500 \mu \mathrm{g}$ of 8-18C5-hIgG1 as well as HK3-hIgG1 neuroborreliosis control antibody [7] (produced in the same system) and $500 \mu \mathrm{g}$ of human Igs (Kedrion). Three days later, rats were sacrificed and perfused with PBS and 4\% PFA in PBS. Postfixation of dissected spinal cord and brain was carried out with $4 \%$ PFA in PBS at $4{ }^{\circ} \mathrm{C}$.

\section{Histopathology of EAE rats}

PFA-fixed brain and spinal cord tissue was dissected, embedded in paraffin and stained with hematoxylin/ eosin, Luxol fast blue (LFB) myelin stain, and Bielschowsky silver impregnation. After antigen retrieval immunocytochemistry was performed. Details including the quantification are described in the Additional file 1.

\section{Phagocyte activation}

IL-8 production of monocytic THP-1 cell line was analyzed upon stimulation with OMGP antigen (cell bound by HeLa cells) and the presence of OMGP antibody, leading to the formation of immune complexes. Details are described in the Additional file 1.

\section{Statistics}

Prism 6 software from GraphPad was used for statistical analysis. For the identification of statistical differences, unpaired t-test, fishers exact test, Tukey's honest significance test and two-way ANOVA were applied. The data is presented as mean \pm standard error of the mean or standard deviation. $P$-values $\leq 0.05$ were considered significant (" $p \leq 0.05$; ** $\left.p \leq 0.01 ;{ }^{* * * * *} p \leq 0.001\right)$.

\section{Results}

\section{Autoantibodies against OMGP in patients with CNS diseases}

To identify patients with autoantibodies to OMGP, we developed two CBAs, OMGP displayed in the membrane with a transmembrane part (OMGP-TM) or with its physiological GPI anchor (Fig. S1). The quantification of the flow cytometer-based screening is explained in Fig. S1. We noted that in the OMGP-GPI assay, some transfected cells expressed only the upstream EGFP of the construct and do not display OMGP on their surface due to incomplete ribosome skipping (Fig. S1). Therefore, this assay was not used for screening, but for subsequent testing of patients' Abs recognizing OMGP-TM.

In total, 588 serum samples (Table S1) from 474 patients with different CNS diseases and 114 healthy controls (HC) were analyzed with OMGP-TM (Fig. 1). To avoid false-positive results, we set a stringent cut-off and calculated this as mean +6 SDs of the HC group (Fig. 1). None of the healthy controls scored positive. Within the MS/CIS group, 8/353 (2.3\%) showed autoantibodies to

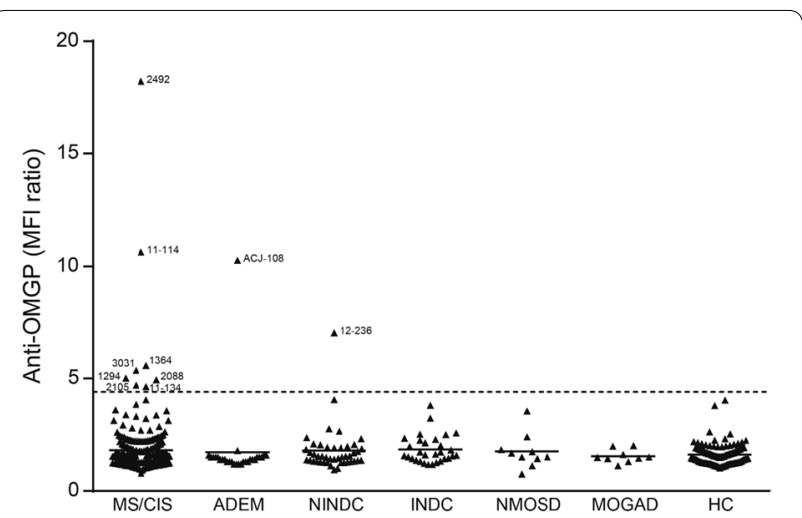

Fig. 1 Identification of patients with Abs to OMGP. A total of 588 sera diluted 1:50 from seven cohorts were screened for OMGP autoantibodies using a cell-based assay (OMGP-TM) displaying OMGP with a transmembrane anchor. The following groups were analyzed: multiple sclerosis/clinical isolated syndrome (MS/CIS, $n=352)$, acute disseminated encephalomyelitis ( $A D E M, n=28$ ), non inflammatory neurological disease control (NINDC, $n=45$ ), inflammatory neurological disease control (INDC, $n=30$ ), neuromyelitis optica spectrum disorders (NMOSD, $n=10$ ), MOG antibody-associated disease (MOGAD, $n=9)$ and healthy controls $(H C s, n=114)$. For the cut off evaluation, HCs were measured twice, except ten HCs samples coming from the Swedish cohort were analyzed once. The horizontal line at 4.4 represents the cut-off as mean plus 6 SDs of the $\mathrm{HC}$ cohort. From patients above the indicated threshold, the symbols show mean value of minimum two replicates. The numbers next to the symbols of the positive patients are the internal code numbers. Clinical details of these patients are in Table S2. ACJ-108 is a child with ADEM, patient 12-236 was diagnosed as psychosis, all other positive patients had MS. Index patient 2492 served as daily control and the value shown is the mean of 30 replicates. The raw data of the anti-OMGP reactivity of patient 2492 is shown in Fig. 2, of all other patients scored positive in Fig. S2

OMGP. When performing a group comparison, we did not detect a significant difference between this group and the HC cohort (two-tailed Fisher's exact test, $p=0.208$ ). One out of 28 pediatric patients (ACJ-108) diagnosed with acute disseminated encephalomyelitis (ADEM) had Abs to OMGP. When we screened sera from 45 non inflammatory neurological disease controls (NINDC), we noted that one patient diagnosed with psychosis (12-236) had Abs to OMGP (Fig. 1). In the inflammatory neurological disease control group (INDC), as well as neuromyelitis optica spectrum disorders (NMOSD) group and patients diagnosed with MOG antibodyassociated disease (MOGAD), no OMGP autoantibodies are detected (Fig. 1). All ten $\mathrm{OMGP}^{+}$patients were analyzed negatively for MOG IgG in our in house CBA [66] and in 4/10 patients AQP4 was also tested negatively throughout clinical routine. From six of the other antiOMGP + patients no AQP4 data was available, since their clinical phenotype was clearly different from NMOSD. 


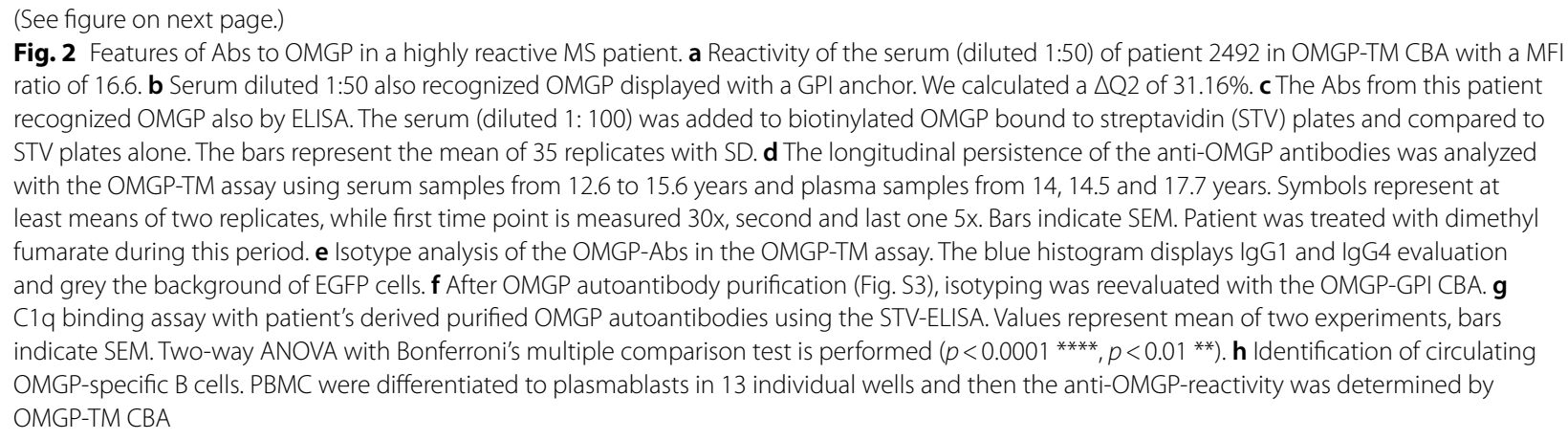

We tested the 10 sera that contained Abs to OMGPTM also with OMGP-GPI and found that sera with a high response to OMGP-TM also showed a clear response to OMGP-GPI; the original FACS data of these 10 patients are shown in Fig. S2 and Fig. 2a, b. The clinical features of these patients are summarized in Table S2. The antiOMGP response was IgG1 in all patients; some had in addition OMGP-specific IgG4 (Fig. 2 and Fig. S2).

We analyzed patient 2492 (index patient) with the highest response to OMGP in our cohort in detail (Fig. 2). This patient with RRMS for 18 years recognized OMGP-TM (Fig. 2a), OMGP-GPI (Fig. 2b) and OMGP by ELISA (Fig. 2c). We could analyze his autoantibodies to OMGP for the last 5 years and found that they persisted (Fig. 2d). The antibodies detectable in serum were of the IgG1 isotype (Fig. 2e). After affinity-purification of the OMGP-specific antibodies (Additional file 1, Fig. S3), we detected in addition to the IgG1 also OMGP-specific IgG4 (Fig. 2f). The affinity-purified Abs from this patient bound significantly more $\mathrm{C} 1 \mathrm{q}$ than the control Abs (Fig. 2g). Furthermore, by differentiating circulating B cells in vitro to plasmablasts, we could also detect circulating OMGP-specific B cells in the blood of this patient (Fig. 2h).

\section{OMGP-specific T cells in patients with MS}

To analyze the presence of OMGP-specific $T$ cells in blood, we applied a recently developed highly sensitive assay for $\mathrm{CD}^{+} \mathrm{T}$ cells, in which the antigen is coupled to beads and multicolor FluoroSpot analysis of cytokine production by single cells is used as a read-out system [8]. We analyzed a new cohort of 28 MS patients (12 treated with natalizumab, since these patients might have enhanced numbers of autoreactive T cells in blood [8,32] and 16 untreated) and 13 healthy controls (Table S3) by multicolor analysis with simultaneous detection of IFN $\gamma$, IL-17A, and IL-22. All three groups produced comparable levels of IFN $\gamma$ and IL-17A upon anti-CD3 stimulation
(Fig. S4A). Only for IL-22, the natalizumab group produced less. To quantify OMGP-specific $\mathrm{T}$ cells, $\Delta \mathrm{SFU}$ were calculated by background subtraction of Avi-His coupled beads, as in a previous study using MOG-coupled beads [8]. For each cytokine a cut-off was calculated by the mean of $\mathrm{HC}$ values plus three SDs. Using these criteria, we found low levels of OMGP-specific T cells producing IFN $\gamma$, IL-22 and/or IL-17A in 1/12 natalizumab treated MS patients, 4/16 untreated MS patients, but in none of 13 healthy controls (Fig. S4B).

\section{High levels of a soluble form of OMGP is found in human CSF}

In this study we generated new OMGP-specific mAbs, namely 14A9 (rat IgG2b), 31A4 (mouse IgG2b), 22H6 (rat IgG2a), 22H6-hIgG1, which were compared the commercially available MAB1674 (Fig. S5). These mAbs were analyzed in CBA (Fig. S5A), as well as OMGP-STV ELISA (Fig. S5B) and reacted comparable to MAB1674.

To evaluate the presence of a soluble form of OMGP (sOMGP), we have developed an ELISA, using one of our new mAbs (14A9) and a commercially available polyclonal $\mathrm{Ab}$ for detection (Fig. S6). We found that sOMGP was abundantly present in each of the analyzed $92 \mathrm{CSF}$ samples (Table S4) with an overall mean of $151 \mathrm{ng} / \mathrm{ml}$. Samples from INDCs, NINDCs as well as CIS, RRMS and SPMS patients had similar levels of sOMGP in the CSF (Fig. 3a). We analyzed, if the levels of sOMGP in the CSF were related to acute inflammation. To this end, we have compared six samples from CIS patients during active disease with 11 samples of CIS patients during remission and noted no difference. Also, the sOMGP levels of 8 RRMS patients obtained during relapse with the samples from 16 RRMS patients taken during remission did not show a difference. To appreciate the high level of sOMGP, we included RRMS and control values for comparison to other CNS proteins previously measured in 


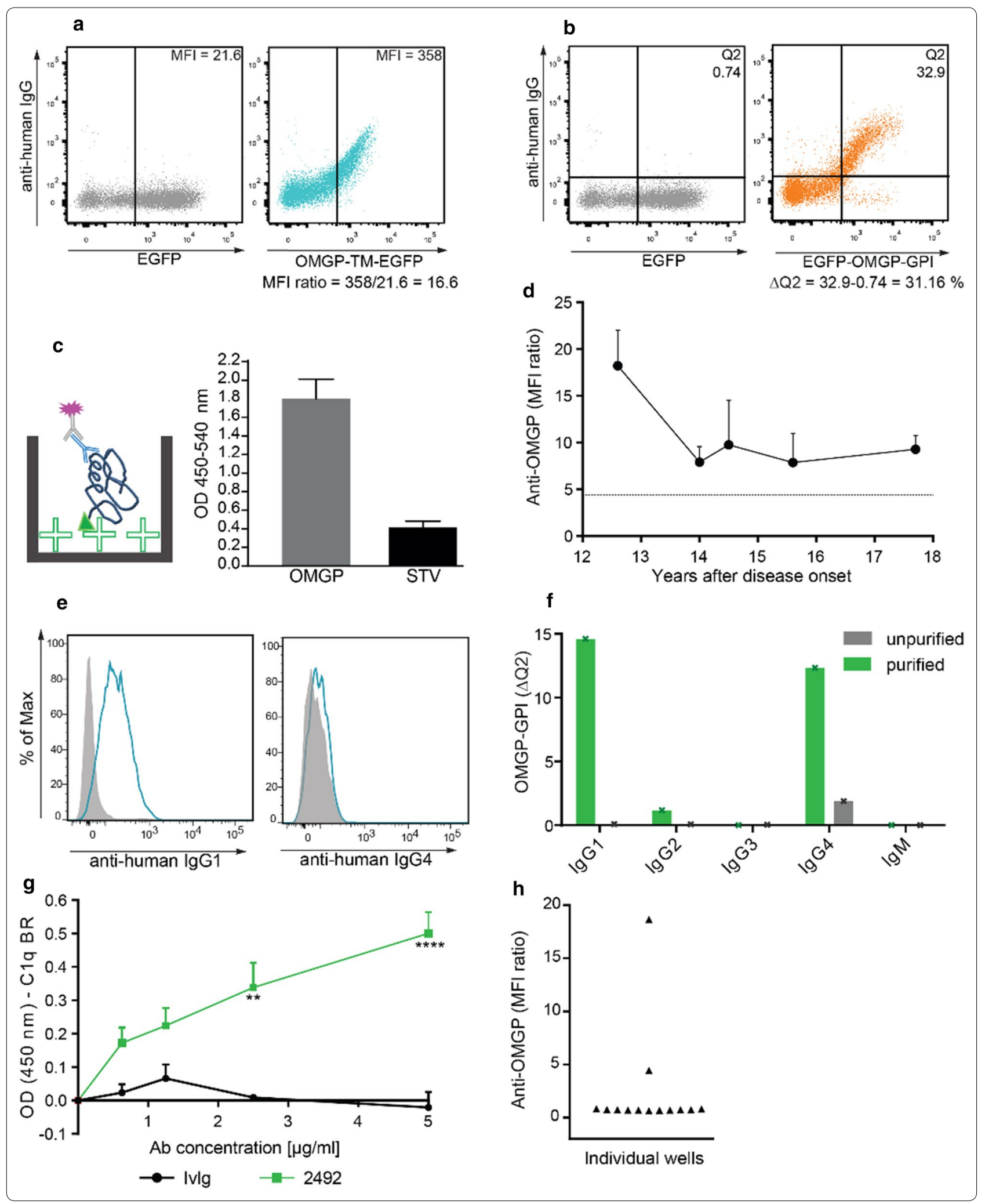




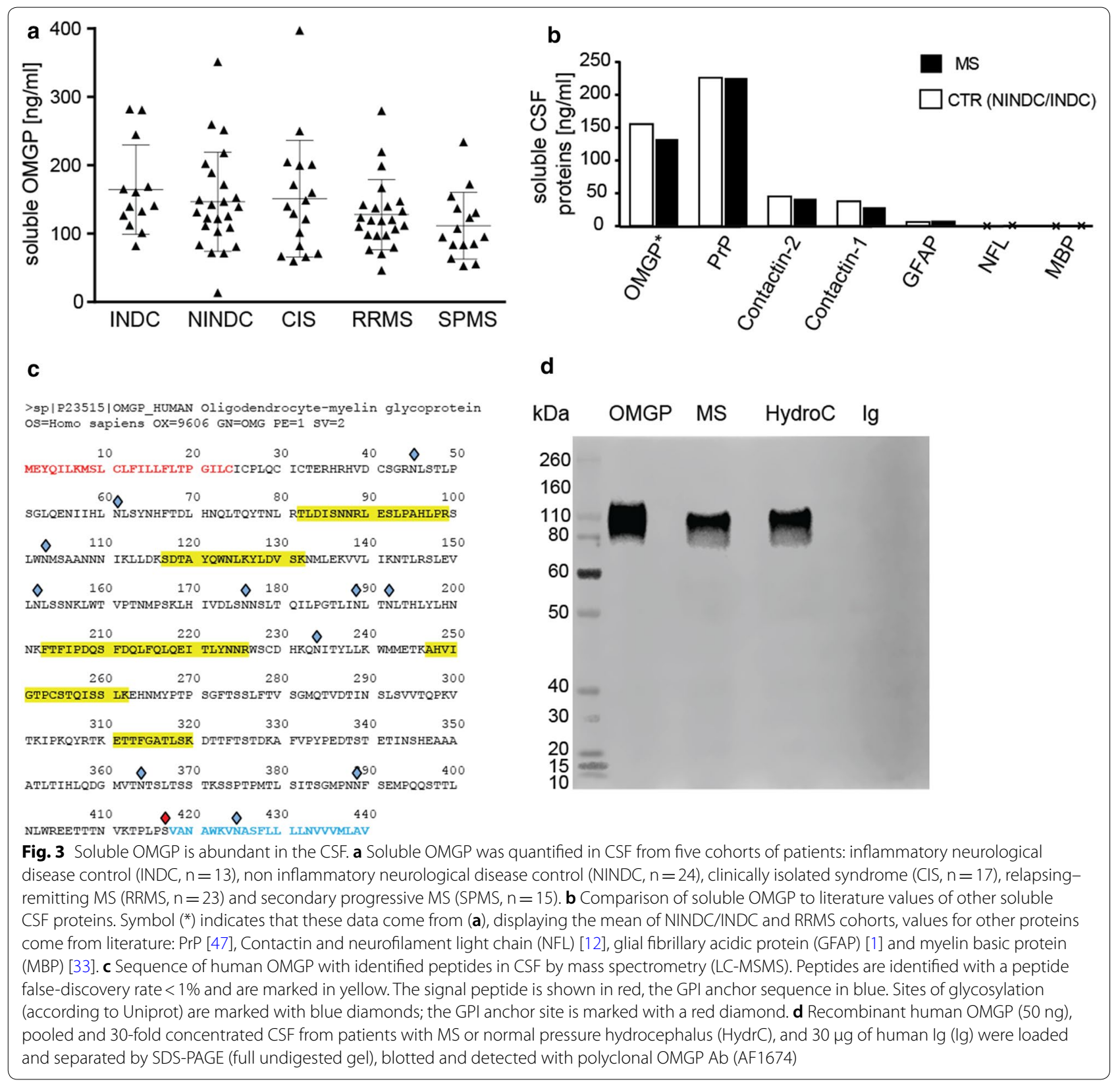

other studies (Fig. 3b). This shows that PrP is present in a similar, slightly higher concentration [47] and two other GPI-anchored proteins, contactin-1 and contactin- 2 were about 3-5 times lower [12] than sOMGP. Levels of GFAP [1], MBP and NFL [12,33] were more than 10-100 fold lower than the level of sOMGP in the CSF. We found no correlation between the sOMGP concentration and the age of patients.

We went on to analyze the sOMGP in the CSF in more detail. By mass spectrometry, we detected five peptides of OMGP (Fig. 3c). Western blot of CSF of patients with MS or hydrocephalus revealed a molecular weight of about $105 \mathrm{kDa}$, the full length of OMGP (Fig. 3d).

\section{Expression of OMGP by neurons, immature and mature oligodendrocytes}

Using primary cultures from mice, we saw OMGP on $\mathrm{O}_{4}^{+}$immature oligodendrocytes and mature $\mathrm{MBP}^{+}$oligodendrocytes with a branching morphology (Fig. $4 \mathrm{a}-\mathrm{c}$ ). All three mAbs 31A4, 14A9 and 22H6 were used for staining and gave a similar pattern, 22H6 is displayed as representative example. We detected OMGP also in 
(See figure on next page.)

Fig. 4 OMGP is displayed by neurons, immature and mature oligodendrocytes. Primary mouse oligodendrocyte precursor cells (OPC) (a) were differentiated for $24 \mathrm{~h}$ (b) or $48 \mathrm{~h}$ (c). A double staining was performed for OMGP (22H6) with the early oligodendroglial marker $\mathrm{O} 4(\mathbf{a}, \mathbf{b})$, or MBP indicating differentiated oligodendrocytes (c). d Mouse cortical neurons (CTN) as well as (e) hippocampal neurons (HPN) were double-stained with the neuron-marker $\beta$-III-tubulin and OMGP $(22 \mathrm{H} 6)$. (a-e) scale bars represent $20 \mu \mathrm{m}$ and white rectangles mark the zoomed area. (F) Spinal cord tissue sections of $55 \mu \mathrm{m}$ were stained with anti-OMGP $(22 \mathrm{H} 6$, red) and $\beta$-III-tubulin (green) for visualization in grey matter. Images are stacks from confocal microscopy with 60x magnification and white scale bar indicates $50 \mu \mathrm{m}$. $\mathbf{g}$ Human oligodendrocytes were double-stained with anti-OMGP (22H6-hlgG1) and O4. Quadrants were set with human lgG and secondary Abs as control

cortical (Fig. 4d) and hippocampal neurons (Fig. 4e). $\beta$-III-tubulin was used as neuronal marker. OMGP was detected surrounding neuronal somata as well as in neurites (Fig. 4d, e). In situ, we stained OMGP in spinal cord neurons (Fig. 4f). Finally, we analyzed the expression of OMGP in human oligodendrocytes obtained through differentiation of iPSC [17]. OMGP was detected on $\mathrm{O}^{+}{ }^{+}$and $\mathrm{O}_{4}^{-}$cells in these oligodendrocyte cultures (Fig. 4g). This part of our work confirms previous studies in rodents $[11,25,30,48]$ and extends it to human oligodendrocytes.

\section{Massive meningitis above the cortical convexities induced by OMGP-specific T cells}

The transfer of OMGP-specific $\mathrm{T}$ cells into Lewis rats induced an inflammation in the CNS with an unusual distribution of the infiltrates (Fig. 5a). There was massive meningitis over the cerebral cortex, but little inflammation in the meninges covering the cerebellum. OMGPspecific $\mathrm{T}$ cells induced meningitis with some spread into the Virchow-Robin space of large cortical vessels. The inflammatory reaction was largely present in three areas of the CNS, namely the cortex, the medulla oblongata (next to the fourth ventricle) and in the gray matter in the spinal cord (Fig. 5a).

In the spinal cord, the inflammation was most prominent in the gray matter of the dorsal horn and around the central canal. The inflammation was largely composed of $\mathrm{T}$ cells with little contribution of $\mathrm{ED}^{+}\left(\mathrm{CD} 68^{+}\right)$macrophages (Fig. 5a). During this study, we observed this histological pattern in a total of 22 rats comprising 3 rats that received only OMGP-specific $\mathrm{T}$ cells alone, 11 rats that received in addition control Igs and 8 rats received OMGP Abs (Table S5 displays animals used in this study). All the animals with OMGP-specific T cells alone, plus control Abs or OMGP Abs, did not show any difference (Fig. S7A). The typical EAE scores, which largely reflect paresis due to spinal cord lesions but do not indicate cortical deficits, were zero.

A very different pattern of inflammation was induced by MBP-specific $\mathrm{T}$ cells (Fig. 5b). Here, hardly any inflammation was seen in the cortex, but massive in the spinal cord, cerebellum and medulla oblongata. The infiltrates were located perivascular and in the parenchyma, and were associated with a large recruitment of macrophages. Our quantitative analysis of the histological stainings elaborate the difference between the pathology mediated by MBP- and OMGP-specific T cells (Fig. 5c): OMGP-specific $\mathrm{T}$ cells induce a significantly stronger inflammation in the meninges over the cortical convexities, while MBP-specific $\mathrm{T}$ cells induce a significantly stronger inflammation in the spinal cord.

As a further control we used T cells specific for OVA (6 rats) which were included in the histological quantification (Fig. 5c). These T cells did not induce inflammation, neither the T cells alone $(n=3)$ nor with control antibodies (IvIg, $\mathrm{n}=3$ ) or with the humanized anti-MOG mAb 8-18C5-hIgG1, as it was shown in our previous study [66].

Having seen that MBP-specific and OMGP-specific $\mathrm{T}$ cells mediate a different pathology, we analyzed if this could be linked to different cytokine profile or surface markers. We found that OMGP-, MBP-, and also OVA-specific $T$ cells express the same surface proteins (Fig. S7B): $\mathrm{CD} 4^{+}, \alpha \beta \mathrm{TCR}^{+}$, activation markers $\mathrm{CD} 25^{+}$ and $\mathrm{CD} 134^{+}$, as well as adhesion molecules $\mathrm{CD} 44^{+}$, $\mathrm{CD} 11 \mathrm{a} / \mathrm{b}^{+}, \mathrm{CD} 49 \mathrm{~d}^{+}$and are negative for naïve markers $\mathrm{CD}^{2} 5 \mathrm{RA}^{-} / \mathrm{CD}_{4} \mathrm{RC}^{-}$. Additionally, these three $\mathrm{T}$ cell lines share the same cytokine profile (Fig. S7C): They were largely Th1 cells with a strong IFNY production with a little contribution of IL17. Arguing that the different pathology induced by MBP- and OMGP-specific T cells is due to their antigen-specificity, since these $\mathrm{T}$ cell lines express similar surface and activation markers.

\section{Priming for anti-MOG mediated demyelination by OMGP-specific T cells}

We tested whether OMGP-specific $\mathrm{T}$ cells breach the blood-brain barrier and synergize with MOG-specific Abs to mediate demyelination. To this end, six animals received systemically OMGP-specific $\mathrm{T}$ cells. Two days later, three of them received intrathecally the humanized MOG-specific mAb 8-18C5-hIgG1 and three human control immunoglobulin (IvIg). The co-transfer of 8-18C5-hIgG1 induced slight clinical symptoms (mean score 0.3 at day 5 of 3 animals), while the control animals with the IvIg did not get sick. OMGP-specific T cells with control Abs induced inflammation, but no demyelination 


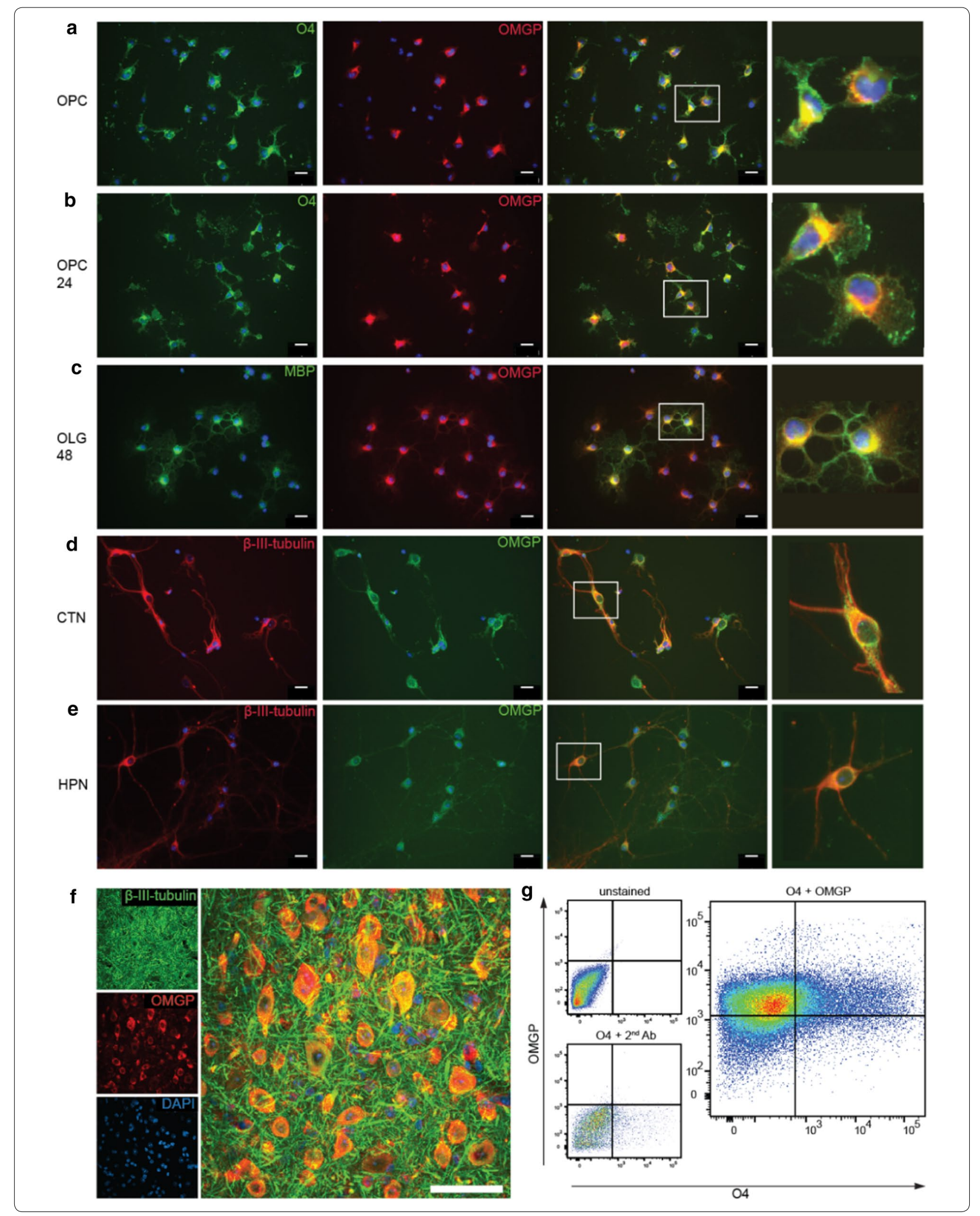




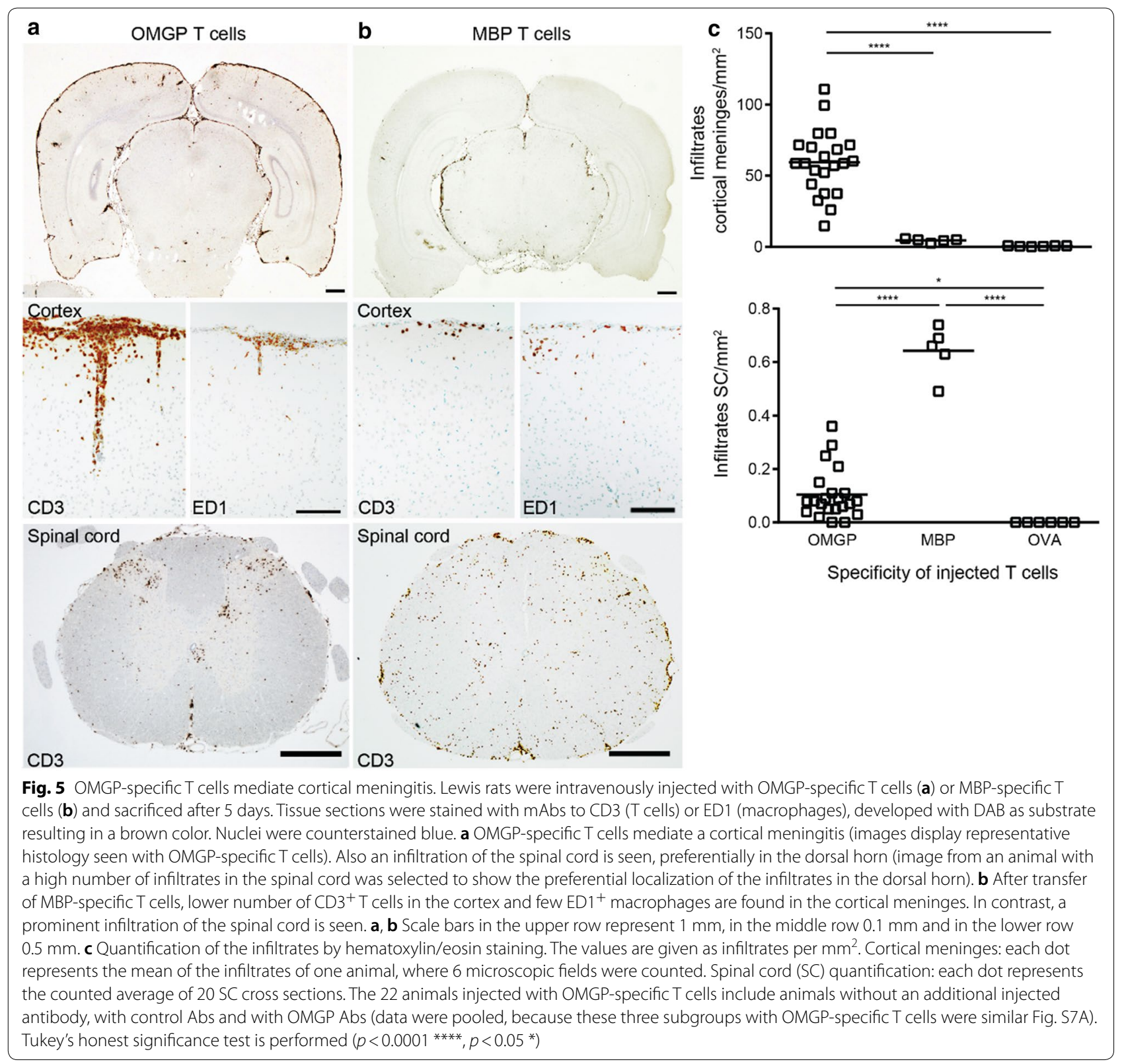

(Fig. 6a), while OMGP-specific T cells plus anti-MOG resulted in demyelination (Fig. 6b). The demyelinating lesions were found either in the white matter (Fig. 6b, upper row) or comprised both white and gray matter (Fig. 6b, lower row). In the spinal cord the lesions were perivascular as well as subpial, related to perivascular or meningeal inflammatory infiltrates. As shown before, subpial demyelination in a MOG antibody driven pathogenesis is in general not associated with major damage of the glia limitans, since the glia limitans is not a diffusion barrier for proteins, such as antibodies or complement from the CSF into the brain. However, the glia limitans may be infiltrated by immune cells in some of the lesions. The quantification of the spinal cord demyelination is displayed in Fig. 6c. As reported previously, no demyelination was observed when the mAb 8-18C5-hIgG1 was given together with OVA-specific T cells [66].

OMGP-specific T cells plus MOG-Ab 8-18C5-hIgG1 induced also demyelinating lesions in the cortex (Fig. S8A), whereas the human control Igs did not (Fig. S8B). These lesions showed a massive inflammation (H\&E, CD3), with little activation of macrophages (ED1), but massive Iba1 activation (phenotypically microglia). There was a loss of CNP (2,3'-cyclic nucleotide 3' 
a OMGP T-cells \& Co ig
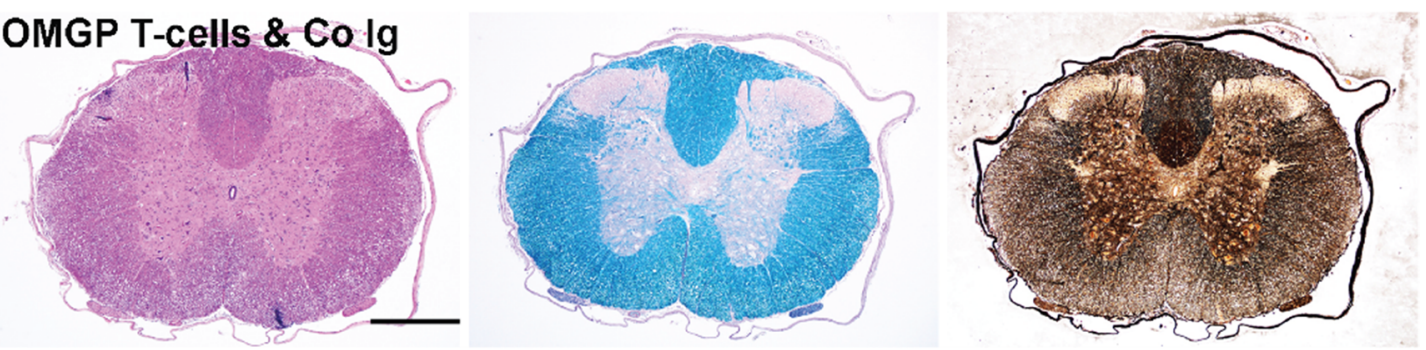

b OMGP T-cells \& $818 \mathrm{C} 5$
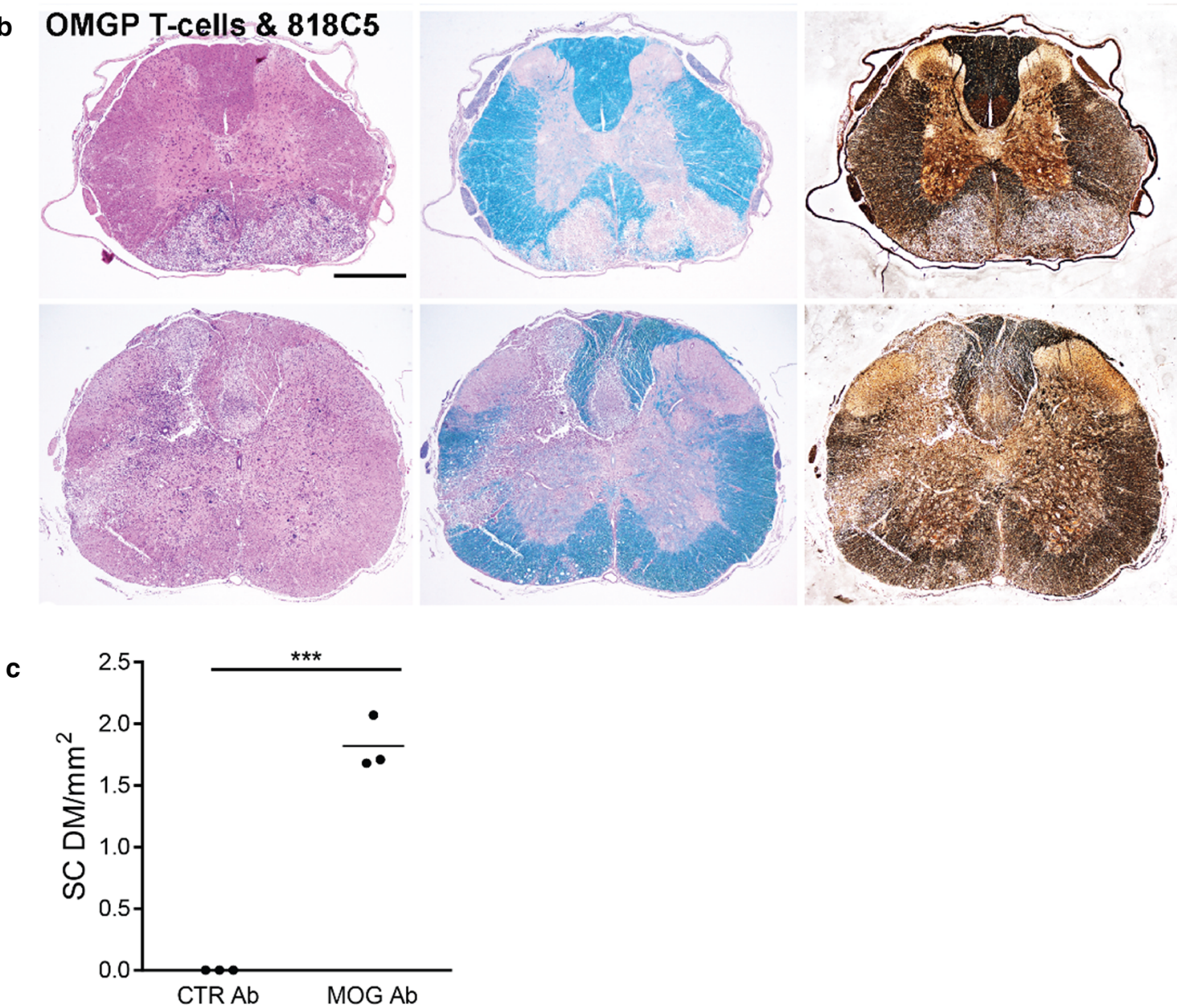

Fig. 6 OMGP-specific T cells pave the way for anti-MOG mediated demyelination in gray and white matter of the spinal cord. Lewis rats were injected with OMGP-specific T cells, 2 days later either a control lg (lvlg) (a) or the MOG-Ab 8-18C5-hlgG1 (b) was given and after 3 more days, the animals were sacrificed. Cross sections of the spinal cord were stained with H\&E (left), LFB (middle), or Bielschowsky's Silver Staining (right). $\mathbf{b}$ T cells injected together with MOG antibody (8-18C5-hlgG1), demyelination and neuronal destruction shown by Bielschowsky's staining. Large demyelinating areas are seen in the white matter (upper part of $\mathbf{b}$ ) and in white plus gray matter (lower part of $\mathbf{b}$ ) along with axonal injury. Scale bar represents $1 \mathrm{~mm}$. c Spinal cord (SC) demyelination (DM) was quantified from the LFB staining. The area of DM is shown in $\mathrm{mm}^{2}$ per SC section. $\left(p<0.001^{* * *} ;\right.$ t-test $)$

phosphodiesterase) and MOG positive myelin, without a loss of oligodendrocytes. Within these lesions, there was a massive deposition of the injected human Ig and of C9neo along with rat IgG, reflecting the breached blood-brain barrier. We also noted a partial loss of AQP4; this is a consequence of gliosis, since under inflammatory conditions, protoplasmic astrocytes are enlarged, which express a lot of GFAP and partially lose their extensions, 
where AQP4 is mostly localized [63]. Further, there was a subpial decoration of myelin with the injected MOGspecific human IgG (Fig. S8). There was very little or no subpial demyelination, but the demyelination was mainly seen in perivascular spaces around larger cortical vessels. The reason for this observation is not entirely clear, but may be related to the fact that macrophage infiltration and complement activation mainly occurred around inflamed vessels (Fig. S4). It is likely that inflammatory cells and mediators, such as complement, reach higher concentrations around inflamed parenchymal vessels, while when present in the subarachnoid space, they are diluted and washed away by CSF and CSF flow.

We also tested by MOG ELISA the presence of the injected 8-18C5-hIgG1 in the serum of the rats when they were sacrificed: All sera from the three animals injected with the 8-18C5-hIgG1 were highly positive for MOG Abs in the peripheral blood, whereas the rats injected with control antibodies did not show a signal above background. Thus, the intrathecally injected IgG was detected in serum and could mediate demyelination by entering areas with disturbed blood-brain barrier from the blood stream explaining the perivascular IgG deposition seen in Fig. S8A. In addition, the MOG-Abs may also diffuse along the perivenous spaces from the subarachnoid space into the tissue.

\section{No demyelination, but activation of phagocytes mediated by Abs to OMGP}

We tested, whether anti-OMGP-Abs mediate demyelination as we observed for MOG-Abs. We applied five different OMGP-specific mAbs, namely 14A9 (rat IgG2b), 31A4 (mouse IgG2b), 22H6 (rat IgG2a), 22H6-hIgG1, which were generated in this study and the commercially available MAB1674. These mAbs cross-react with rodent OMGP as seen by cell-based assay, also recognized OMGP by ELISA, had different isotypes and accordingly different binding to $\mathrm{C} 1 \mathrm{q}$ (Fig. S5). We injected 2 days after the transfer of encephalitogenic MBP-specific T cells, $500 \mu \mathrm{g}$ of the OMGP-mAbs 14A9, 31A4, 22H6, or isotype specific control Abs intrathecally (Table S5). The animals were sacrificed 3 days later and analyzed histologically. None of these antibodies induced demyelination under these conditions. For comparison, 8-18C5-hIgG1 was used, which induced a strong demyelination in the context of MBP-specific T cells, as seen in a previous study [66].

Since we found that OMGP-specific T cells open the blood-brain barrier and paved the way for anti-MOG mediated demyelination (Fig. 6 and Fig. S8), we also injected OMGP-specific mAbs together with OMGP-specific T cells. We used MAB1674 and our new mAb 22H6 (rIgG2a). None of these Abs induced demyelination, whereas 8-18C5-hIgG1 induced a strong demyelination as seen before (Fig. 6). Since the 8-18C5-hIgG1 had a human IgG1 backbone, which strongly activates complement, we cloned the mAb $22 \mathrm{H} 6$ in the same vector and produced it recombinantly, 22H6-hIgG1. Indeed, this enhanced the C1q binding to 22H6-hIgG1 mAb (Fig. S5C), but injection along with OMGP-specific $\mathrm{T}$ cells did not induce demyelination. Together, all these experiments indicate that Abs to OMGP did not mediate demyelination, in contrast to the anti-MOG-mAb 8-18C5-hIgG1.

Since certain mAbs enhance immune cell activation after binding to their antigen $[20,66]$, presumably by binding of immune-complexes to FcR [35], we tested in vitro the activation of phagocytes by an OMGP mAb in the presence of its antigen. For these experiments, we used 22H6-hIgG1 and the human phagocyte cell line THP-1. We observed that this OMGP-specific Ab activated these phagocytes in the presence of its antigen as seen by induced secretion of IL-8 (Fig. S9).

\section{Discussion}

We report here that (1) autoimmunity to OMGP can be detected in a proportion of patients with inflammatory diseases of the CNS, (2) high levels of sOMGP are constitutively present in the CNS and (3) OMGP-specific T cells mediate a novel type of EAE with inflammation in the meninges of the cortical convexities.

To analyze the presence of autoimmunity to OMGP in patients with inflammatory CNS diseases, we have established a live cell-based assay, since autoantibodies against membrane-anchored proteins are in many instances reliably detected with cell-based assays [38,60]. We used a stringent cut-off to exclude potential false positive ones in this first report of OMGP autoimmunity. We found that 8/353 (2.3\%) MS patients, $1 / 28$ (3.6\%) of children with ADEM have autoantibodies against OMGP, but none of the healthy donors. Since OMGP is GPI-anchored, we confirmed recognition of OMGP by displaying OMGP in its GPI-linked form. We noted that also one patient diagnosed with psychosis showed a clear autoantibody response to OMGP. Our observations that autoimmunity to OMGP induces cortical pathology in an animal model, might inspire larger studies to learn whether there is a subset of psychosis patients with auto-Abs to OMGP. In children with ADEM, around $20 \%$ of the patients have Abs to MOG [53]. Our observation that $1 / 28$ children with ADEM has auto-Abs to OMGP is compatible with the view that different autoantigens are targeted in these patients. We noted that the 10 patients with Abs to OMGP we identified did not show a striking common phenotype. This is similar to experiences with anti-MOG and anti-GAD65. Abs to MOG are found in patients with 
different clinical phenotypes such as childhood ADEM with encephalopathy $[46,53]$, isolated optic neuritis [59], NMOSD [44, 60, 81], rarely in patients fulfilling the criteria of MS [65] and in cortical encephalitis with epilepsy [54]. A consensus is emerging that despite these clinically different features, patients with MOG-Abs should be grouped as a separate disease [44, 81]. Also, patients with anti-GAD65 show different neurological syndromes like stiff person syndrome, cerebellar ataxia, limbic encephalitis, epilepsy, or oculomotor dysfunction [38, 71]. The different localizations of OMGP and our animal model, showing that autoimmunity to OMGP can result in cortical encephalitis/meningitis, lesions in the spinal cord and may pave the way for demyelination by antibodies of a different specificity, might explain why different clinical features can be associated with autoimmunity to OMGP. Further samples should be analyzed to establish the spectrum of syndromes associated with autoimmunity to OMGP.

The isotype of anti-OMGP-Abs was largely IgG1, similarly as anti-MOG or anti-AQP4. In some patients we noted in addition to the IgG1 also an IgG4 response. The IgG4 contribution to OMGP-specific Abs we could formally prove with affinity-purified Abs from a highly reactive MS patient. IgG4 is at the end of the possible IgG switch-chain in humans (IgG3 $\rightarrow$ IgG1 $\rightarrow$ IgG2 $\rightarrow$ IgG4) and typically indicates repeated antigen exposure [75]. A co-occurrence of IgG1 and IgG4 has also been observed in patients with CASPR2-specific Abs [74]. Since isotype switching to IgG1 and IgG4 is typically the result of a germinal center reaction involving cognate $\mathrm{T}$ cell help, this indicates the presence of OMGP-specific $\mathrm{T}$ cells in these patients.

We set out to get a first insight into OMGP-specific $\mathrm{T}$ cells using a recently developed highly sensitive technology to detect $\mathrm{CD} 4^{+} \mathrm{T}$ cells, which applies bead-coupled antigens and uses a multicolor FluoroSpot as read-out [8]. Thereby, we could detect OMGP-specific $\mathrm{T}$ cells in MS patients secreting IFN $\gamma$, IL-22 or IL-17A at low frequency. This low frequency of autoreactive $\mathrm{T}$ cells is consistent with previous experiences with MS and other human autoimmune diseases [28, 29]. For technical reasons the identification of patients with an antigenspecific autoimmune response is typically done by measuring autoantibodies (e.g. against MOG or AQP4) rather than quantifying the low frequency autoantigen-specific $\mathrm{T}$ cells. In contrast to autoimmune diseases, in certain infectious diseases like tuberculosis, the measurement of the high frequency of microbe-specific $\mathrm{T}$ cells is of diagnostic relevance [50]. The future application of further technologies such as libraries of amplified $\mathrm{T}$ cells $[10,22]$, peptide libraries [32] and tetramers detecting $\mathrm{CD} 8^{+} \mathrm{T}$ cells [62] will give a deeper insight into features of OMGP-specific T cells. In addition, antigen-specific tolerance is a promising specific future therapy $[43,69]$. OMGP is a novel candidate antigen to be included in future cocktails for antigen-specific therapy.

Further, we found that a soluble form of OMGP is constitutively present in enormously high amounts in the CSF. sOMGP was recently detected in the supernatant of neuronal and even more in oligodendrocyte cultures [72]. The levels of sOMGP we measured in the CSF are about 10-100-fold higher than previously reported for MBP [33], GFAP [1] or neurofilament light chain [12]. We found that the levels of sOMGP were not further elevated during a relapse; this is presumably due the enormously high basal level of sOMGP, which is orders of magnitude higher than that of MBP; therefore increased levels of MBP are seen in active disease, but not of OMGP. The presence of sOMGP in human [16] and murine [72] CSF was noted in previous proteomic studies. A similar abundance in the CSF as we observed for OMGP has been reported for PrP, contactin-1, and contacin-2 [47, 73]. All of these proteins are GPI-anchored. OMGP was previously found to be released by exogenously added phosphatidylinositol-specific phospholipase C (PI-PLC) $[48,76]$. GPI-linked proteins can principally also be shed by ADAM proteases as has been worked out for PrP [40]. The size of sOMGP we found in the CSF (105 kDa) is basically full-length and compatible with cleavage of OMGP by a lipase or by an ADAM protease close to the membrane, but the biochemical details of the shedding of OMGP have yet to be elaborated.

We tested the pathogenic potential of OMGP-specific $\mathrm{T}$ cells and mAbs to OMGP in an animal model in the Lewis rat. Strikingly, OMGP-specific T cells induce a novel type of EAE characterized by infiltrations in meninges around the cortical convexities. This localization is very different from the localization mediated by MBPspecific $\mathrm{T}$ cells [6]. We assume that this unusual localization of the inflammatory lesions is due to the enormous levels of sOMGP in the spinal fluid. From there it is taken up by meningeal macrophages and presented to OMGPspecific T cells. We suppose that sOMGP in the CSF is derived from both neurons and oligodendrocytes. We saw OMGP in rodent $\mathrm{O}^{+}$oligodendrocyte progenitor cells and $\mathrm{MBP}^{+}$mature oligodendrocytes, consistent with the localization of OMGP in myelin [11] and oligodendrocytes $[25,30]$. We extend this by showing that also human iPSC-derived oligodendrocytes (both $\mathrm{O}^{+}$ and $\mathrm{O}^{-}$cells) express OMGP. We also detected OMGP in cultured neurons, which is consistent with the immunohistochemical localization of OMGP in neurons of the dorsal horn of the spinal cord and of the hippocampus [25]. We propose that sOMGP is transported to the 
perivascular space and the CSF by interstitial flow [31, 67] and then taken up by perivascular and meningeal macrophages [3, 19, 34]. In the presence of OMGP-specific $\mathrm{T}$ cells, this results in cortical meningitis. It has been shown that leptomeningeal macrophages present local myelin to encephalitogenic T cells $[5,37]$.

The second pathological feature of autoimmunity to OMGP, inflammation in the gray matter of the spinal cord, might be based on neuronal expression of OMGP. In inflammatory diseases of the CNS, precise localization of the lesions is determined by the site of antigen expression: For example, T cells specific for MBP induce inflammation largely in the white matter of the lumbar spinal cord [6] while $T$ cells against contactin-2 [15] and $\beta$-synuclein [42], which are found in gray matter, target the inflammatory response to the gray matter. We found OMGP in spinal cord neurons in situ, which might be shed and subsequently presented by adjacent microglia to OMGP-specific $\mathrm{T}$ cells.

The third feature of OMGP-specific $\mathrm{T}$ cells is opening of the blood-brain barrier and paving the way for demyelination by MOG-Abs. Similar synergy of encephalitogenic $\mathrm{T}$ cells and MOG-Abs has been observed in several models [15, 23, 41, 66]. Together with OMGP-specific $\mathrm{T}$ cells, we observed a strong perivenous confluent demyelination, associated with Ig-deposition and complement activation. The anti-MOG Ab induces this demyelination most likely by entering from the periphery although we had applied the Ab intrathecally, since we observed high levels of anti-MOG reactivity also in the serum after intrathecal application.

Since evidence has been provided that OMGP is expressed on the outside of myelin [11] like MOG [60], we addressed the question whether antibodies against OMGP would mediate demyelination as antibodies to MOG [66]. We have tested four different mAbs specific for OMGP for inducing demyelination in combination with $\mathrm{T}$ cells specific for MBP or OMGP that breach the blood-brain barrier. These anti-OMGP mAbs had different isotypes and included also complement activating isotypes seen by $\mathrm{C} 1 \mathrm{q}$ binding. None of the anti-OMGP mAbs induced demyelination. In order to exclude the possibility that all of our anti-OMGP mAbs just lack the appropriate Fc part to activate the effector mechanisms mediating demyelination, we cloned the Ig chains from one of them and produced the Ab recombinantly with the same human IgG1-Fc part as our recombinant MOG-Ab 8-18C5-hIgG1, which we used as a positive control [66]. The recombinant OMGP$\mathrm{Ab}$ with a human IgG1 had an enhanced $\mathrm{C} 1 \mathrm{q}$ binding, but also this mAb did not mediate demyelination. Together, all our experiments argue that anti-OMGP mAbs do not mediate demyelination in contrast to
anti-MOG mAbs. The high level of sOMGP in the CSF (and presumably also in the brain parenchyma) might absorb the anti-OMGP Abs thus preventing Ab-mediated demyelination. Also, shedding of OMGP might be induced by Ab-binding. Alternatively, we cannot exclude that the affinity to rat OMGP of the mAbs we tested was too low, although we detected a cross-reactivity to rodent OMGP. Autoantibodies can be pathogenic by different mechanisms including complement activation [64] and enhancing activation of cognate $\mathrm{T}$ cells $[20,35,66]$. Further, immune complexes might activate phagocytes inducing inflammation. Along this line, we found that a mAb against OMGP enhanced phagocyte activation in the presence of OMGP raising the possibility that OMGP-specific Abs might contribute to cortical meningitis.

Together, this study describes OMGP as an autoantigen in a proportion of patients with inflammatory CNS disorders and shows in an animal model that OMGP-specific $T$ cells mediate a novel type of EAE characterized by meningitis above the cortical convexities. Identification of autoimmunity to OMGP might be of future relevance to stratify patients with CNS inflammation.

\section{Supplementary information}

Supplementary information accompanies this paper at https://doi. org/10.1186/s40478-020-01086-2.

Additional file 1. Supplementary Methods. Fig. S1. Cell-based assays to detect antibodies to OMGP. Fig. S2. Reactivity to OMGP in both CBAs and isotypes of OMGP-specific Abs of patients scored positive. Fig. S3. Affinity-purification of OMGP-specific Abs from MS patient 2492. Fig. S4. Fluorospot assay identifies MS patients with OMGPspecific T cells. Fig. S5. Characterization of new mAbs to OMGP. Fig. S6. ELISA to detect sOMGP. Fig. S7. Characterization of OMGP-specific T cells. Fig. S8. OMGP-specific T cells pave the way for focal demyelination in the cortex. Fig. S9. Immune complexes of OMGP and anti-OMGP activate phagocytes. Table S1. Subjects used for screening of anti-OMGP Abs. Table S2. Clinical characteristics of patients with Abs to OMGP. Table S3. Subjects used for analysis of OMGP-specific T cells. Table S4. Patients used for quantification of sOMGP in the CSF. References $[2,9,18,27,45,49,55-57,77-80]$ are cited in additional file 1.

\section{Acknowledgements \\ We are grateful to Martina Sölch for technical assistance, Dr. Ingrid Meinl, Dr. Joachim Havla, Angelika Bamberger, Sabine Lüngen for patient care, Prof. Martin Kerschensteiner and Prof. Hartmut Wekerle for continuous support. We thank Dr. Florence Bareyre and Dr. Klaus Dornmair for comments on the manuscript.}

\section{Authors' contributions}

EM and NK initiated, designed, supervised the study and wrote the manuscript. RG performed IF staining, CBAs, ELISAs, FluoroSpot assays and wrote the manuscript. LKP performed IF staining and characterized mAbs. JL performed phagocytosis assay. LS, LN, and TK performed IF staining and generated hiOL. FST, MS, LAG, ABO, BB, MK, TO and TK were involved in collection of human samples and clinical characterization of patients. HR, CM, SW, SM performed WB, produced proteins and analyzed data. MB and HG performed FluoroSpot assays and analyzed data. RF generated mAbs in rodents. $\mathrm{HEH}$ 
and SFL generated primary neuronal cell cultures and analyzed data. JMP and SMH performed mass spectrometry and analyzed data. IJB and NK carried out animal experiments. EB performed PCR and humanization of mAb. AM performed IF tissue staining. RH contributed to data analysis and writing of the manuscript. HL performed histology, analyzed data and partly wrote the manuscript. All authors reviewed and edited the manuscript.

\section{Funding}

Open Access funding enabled and organized by Projekt DEAL.. This study was funded by the DFG (SFB TR128) and under Germany's Excellence Strategy within the framework of the Munich Cluster for Systems Neurology (EXC 2145 SyNergy- ID 390857198), the Werner Reichenberger Stiftung and the Verein zur Therapieforschung für MS-Kranke.

\section{Availability of data and materials}

All data generated or analyzed during this study are included in this article (and its Additional file 1). The datasets generated during and/or analyzed during the current study are available from the corresponding author on reasonable request.

\section{Ethics approval and consent to participate}

Informed consent was obtained from each donor according to the Declaration of Helsinki and the ethical committee of the medical faculty of LudwigMaximilians-Universität München, the Karolinska-Institute, Stockholm, or the Canadian Paediatric Study Group approved this study. The experiments on Lewis rats were approved by the government of Upper Bavaria.

\section{Consent for publication}

Not applicable.

\section{Competing interests}

$\mathrm{HG}$ is the co-founder of the company TCER AB, which holds patents and pending patents regarding bead-based antigen processing. MB and $H G$ are inventors of said patents. All other authors have nothing to declare in the context of this work.

\section{Author details}

${ }^{1}$ Institute of Clinical Neuroimmunology, Biomedical Center and University Hospitals, Ludwig-Maximilians-Universität München, Großhaderner Str. 9, 82152 Planegg-Martinsried, Germany. ${ }^{2}$ Institute of Neuropathology, University Hospital Münster, Münster, Germany. ${ }^{3}$ Therapeutic Immune Design, Department of Clinical Neuroscience, Karolinska Institutet, Stockholm, Sweden. ${ }^{4}$ Institute for Diabetes and Obesity, Monoclonal Antibody Core Facility, Helmholtz Center Munich, German Research Center for Environmental Health (GmbH), Neuherberg, Germany. ${ }^{5}$ Neuroproteomics, School of Medicine, Klinikum rechts der Isar, German Center for Neurodegenerative Diseases (DZNE), Technical University of Munich, Munich, Germany. ${ }^{6}$ Research Unit Protein Science, Helmholtz Center Munich, Munich, Germany. ${ }^{7}$ Department of Neurology, University of Pennsylvania, Philadelphia, USA. ${ }^{8}$ Children's Hospital of Philadelphia, Philadelphia, USA. ${ }^{9}$ Neuroimmunology Unit, Department of Clinical Neuroscience, Karolinska Institutet, Stockholm, Sweden. ${ }^{10}$ Center for Brain Research, Medical University, Vienna, Austria. ${ }^{11}$ Munich Cluster for Systems Neurology (SyNergy), Munich, Germany.

\section{Received: 11 November 2020 Accepted: 18 November 2020} Published online: 30 November 2020

\section{References}

1. Abdelhak A, Huss A, Kassubek J, Tumani H, Otto M (2018) Serum GFAP as a biomarker for disease severity in multiple sclerosis. Sci Rep 8:14798. https://doi.org/10.1038/s41598-018-33158-8

2. Albrecht S, Korr S, Nowack L, Narayanan V, Starost L, Stortz F, Arauzo-Bravo MJ, Meuth SG, Kuhlmann T, Hundehege P (2019) The K2P -channel TASK1 affects oligodendroglial differentiation but not myelin restoration. Glia 67:870-883. https://doi.org/10.1002/glia.23577

3. Alves de Lima K, Rustenhoven J, Kipnis J (2020) Meningeal immunity and its function in maintenance of the central nervous system in health and disease. Annu Rev Immunol 38:597-620. https://doi.org/10.1146/annur ev-immunol-102319-103410
4. Atwal JK, Pinkston-Gosse J, Syken J, Stawicki S, Wu Y, Shatz C, TessierLavigne M (2008) PirB is a functional receptor for myelin inhibitors of axonal regeneration. Science 322:967-970. https://doi.org/10.1126/scien ce. 1161151

5. Bartholomaus I, Kawakami N, Odoardi F, Schlager C, Miljkovic D, Ellwart JW, Klinkert WE, Flugel-Koch C, Issekutz TB, Wekerle H, Flügel A (2009) Effector T cell interactions with meningeal vascular structures in nascent autoimmune CNS lesions. Nature 462:94-98

6. Berger T, Weerth S, Kojima K, Linington C, Wekerle H, Lassmann H (1997) Experimental autoimmune encephalomyelitis: the antigen specificity of T lymphocytes determines the topography of lesions in the central and peripheral nervous system. Lab Invest 76:355-364

7. Brändle SM, Obermeier B, Senel M, Bruder J, Mentele R, Khademi M, Olsson T, Tumani H, Kristoferitsch W, Lottspeich F, Wekerle H, Hohlfeld $\mathrm{R}$, Dornmair K (2016) Distinct oligoclonal band antibodies in multiple sclerosis recognize ubiquitous self-proteins. Proc Natl Acad Sci U S A 113:7864-7869. https://doi.org/10.1073/pnas.1522730113

8. Bronge M, Ruhrmann S, Carvalho-Queiroz C, Nilsson OB, Kaiser A, Holmgren E, Macrini C, Winklmeier S, Meinl E, Brundin L, Khademi M, Olsson T, Gafvelin G, Gronlund H (2019) Myelin oligodendrocyte glycoprotein revisited-sensitive detection of MOG-specific T-cells in multiple sclerosis. J Autoimmun 102:38-49. https://doi.org/10.1016/j.jaut.2019.04.013

9. Brosch M, Yu L, Hubbard T, Choudhary J (2009) Accurate and sensitive peptide identification with Mascot Percolator. J Proteome Res 8:3176-3181. https://doi.org/10.1021/pr800982s

10. Cao Y, Goods BA, Raddassi K, Nepom GT, Kwok WW, Love JC, Hafler DA (2015) Functional inflammatory profiles distinguish myelin-reactive T cells from patients with multiple sclerosis. Sci Transl Med 7:287ra274. https:// doi.org/10.1126/scitranslmed.aaa8038

11. Chang KJ, Susuki K, Dours-Zimmermann MT, Zimmermann DR, Rasband MN (2010) Oligodendrocyte myelin glycoprotein does not influence node of ranvier structure or assembly. J Neurosci 30:14476-14481. https ://doi.org/10.1523/JNEUROSCI.1698-10.2010

12. Chatterjee $M$, Koel-Simmelink MJ, Verberk IM, Killestein J, Vrenken H, Enzinger C, Ropele S, Fazekas F, Khalil M, Teunissen CE (2018) Contactin-1 and contactin-2 in cerebrospinal fluid as potential biomarkers for axonal domain dysfunction in multiple sclerosis. Mult Scler J Exp Transl Clin 4:2055217318819535. https://doi.org/10.1177/2055217318819535

13. Crawford MP, Yan SX, Ortega SB, Mehta RS, Hewitt RE, Price DA, Stastny P, Douek DC, Koup RA, Racke MK, Karandikar NJ (2004) High prevalence of autoreactive, neuroantigen-specific CD8 + T cells in multiple sclerosis revealed by novel flow cytometric assay. Blood 103:4222-4231. https:// doi.org/10.1182/blood-2003-11-4025

14. Daniels RW, Rossano AJ, Macleod GT, Ganetzky B (2014) Expression of multiple transgenes from a single construct using viral 2A peptides in Drosophila. PLoS ONE 9:e100637. https://doi.org/10.1371/journ al.pone.0100637

15. Derfuss T, Parikh K, Velhin S, Braun M, Mathey E, Krumbholz M, Kümpfel T, Moldenhauer A, Rader C, Sonderegger P, Pollmann W, Tiefenthaller C, Bauer J, Lassmann H, Wekerle H, Karagogeos D, Hohlfeld R, Linington C, Meinl E (2009) Contactin-2/TAG-1-directed autoimmunity is identified in multiple sclerosis patients and mediates gray matter pathology in animals. Proc Natl Acad Sci USA 106:8302-8307

16. Dhaunchak AS, Becker C, Schulman H, De Faria O, Rajasekharan S, Banwell B, Colman DR, Bar-Or A (2012) Implication of perturbed axoglial apparatus in early pediatric multiple sclerosis. Ann Neurol 71:601-613. https:// doi.org/10.1002/ana.22693

17. Ehrlich M, Mozafari S, Glatza M, Starost L, Velychko S, Hallmann AL, Cui QL, Schambach A, Kim KP, Bachelin C, Marteyn A, Hargus G, Johnson RM, Antel J, Sterneckert J, Zaehres H, Scholer HR, Baron-Van Evercooren A, Kuhlmann T (2017) Rapid and efficient generation of oligodendrocytes from human induced pluripotent stem cells using transcription factors. Proc Natl Acad Sci U S A 114:E2243-E2252. https://doi.org/10.1073/ pnas.1614412114

18. Emery B, Dugas JC (2013) Purification of oligodendrocyte lineage cells from mouse cortices by immunopanning. Cold Spring Harb Protoc 2013:854-868. https://doi.org/10.1101/pdb.prot073973

19. Engelhardt B, Vajkoczy P, Weller RO (2017) The movers and shapers in immune privilege of the CNS. Nat Immunol 18:123-131. https://doi. org/10.1038/ni.3666 
20. Flach AC, Litke T, Strauss J, Haberl M, Gomez CC, Reindl M, Saiz A, Fehling HJ, Wienands J, Odoardi F, Luhder F, Flügel A (2016) Autoantibodyboosted T-cell reactivation in the target organ triggers manifestation of autoimmune CNS disease. Proc Natl Acad Sci U S A 113:3323-3328. https ://doi.org/10.1073/pnas.1519608113

21. Friese MA, Fugger L (2009) Pathogenic CD8(+) T cells in multiple sclerosis. Ann Neurol 66:132-141

22. Geiger R, Duhen T, Lanzavecchia A, Sallusto F (2009) Human naive and memory CD4 +T cell repertoires specific for naturally processed antigens analyzed using libraries of amplified T cells. J Exp Med 206:1525-1534. https://doi.org/10.1084/jem.20090504

23. Genain CP, Nguyen MH, Letvin NL, Pearl R, Davis RL, Adelman M, Lees MB, Linington C, Hauser SL (1995) Antibody facilitation of multiple sclerosislike lesions in a nonhuman primate. J Clin Investig 96:2966-2974

24. Geoffroy CG, Zheng B (2014) Myelin-associated inhibitors in axonal growth after CNS injury. Curr Opin Neurobiol 27:31-38. https://doi. org/10.1016/j.conb.2014.02.012

25. Habib AA, Marton LS, Allwardt B, Gulcher JR, Mikol DD, Hognason T, Chattopadhyay N, Stefansson K (1998) Expression of the oligodendrocytemyelin glycoprotein by neurons in the mouse central nervous system. J Neurochem 70:1704-1711

26. Hahn S, Trendelenburg G, Scharf M, Denno Y, Brakopp S, Teegen B, Probst C, Wandinger KP, Buttmann M, Haarmann A, Szabados F, Vom Dahl M, Kümpfel T, Eichhorn P, Gold H, Paul F, Jarius S, Melzer N, Stöcker W, Komorowski L (2017) Identification of the flotillin-1/2 heterocomplex as a target of autoantibodies in bona fide multiple sclerosis. J Neuroinflammation 14:123. https://doi.org/10.1186/s12974-017-0900-z

27. Hauck SM, Dietter J, Kramer RL, Hofmaier F, Zipplies JK, Amann B, Feuchtinger A, Deeg CA, Ueffing M (2010) Deciphering membrane-associated molecular processes in target tissue of autoimmune uveitis by label-free quantitative mass spectrometry. Mol Cell Proteomics 9:2292-2305. https ://doi.org/10.1074/mcp.M110.001073

28. Hohlfeld R, Dornmair K, Meinl E, Wekerle H (2016) The search for the target antigens of multiple sclerosis, part 1: autoreactive CD4 + T lymphocytes as pathogenic effectors and therapeutic targets. Lancet Neurol 15:198-209. https://doi.org/10.1016/s1474-4422(15)00334-8

29. Hohlfeld R, Dornmair K, Meinl E, Wekerle H (2016) The search for the target antigens of multiple sclerosis, part 2: $\mathrm{CD} 8+T$ cells, B cells, and antibodies in the focus of reverse-translational research. Lancet Neurol 15:317-331. https://doi.org/10.1016/s1474-4422(15)00313-0

30. Huang JY, Wang YX, Gu WL, Fu SL, Li Y, Huang LD, Zhao Z, Hang Q, Zhu HQ, Lu PH (2012) Expression and function of myelin-associated proteins and their common receptor $\mathrm{NgR}$ on oligodendrocyte progenitor cells. Brain Res 1437:1-15. https://doi.org/10.1016/j.brainres.2011.12.008

31. Iliff JJ, Wang M, Liao Y, Plogg BA, Peng W, Gundersen GA, Benveniste H, Vates GE, Deane R, Goldman SA, Nagelhus EA, Nedergaard M (2012) A paravascular pathway facilitates CSF flow through the brain parenchyma and the clearance of interstitial solutes, including amyloid beta. Sci Transl Med 4:147111. https://doi.org/10.1126/scitranslmed.3003748

32. Jelcic I, Al Nimer F, Wang J, Lentsch V, Planas R, Jelcic I, Madjovski A, Ruhrmann S, Faigle W, Frauenknecht K, Pinilla C, Santos R, Hammer C, Ortiz Y, Opitz L, Gronlund H, Rogler G, Boyman O, Reynolds R, Lutterotti A, Khademi M, Olsson T, Piehl F, Sospedra M, Martin R (2018) Memory B cells activate brain-homing, autoreactive CD4(+) T cells in multiple sclerosis. Cell 175:85-100.e123. https://doi.org/10.1016/j.cell.2018.08.011

33. Kaneko K, Sato DK, Nakashima I, Nishiyama S, Tanaka S, Marignier R, Hyun JW, Oliveira LM, Reindl M, Seifert-Held T, Sepulveda M, Siritho S, Waters PJ, Kurosawa K, Akaishi T, Kuroda H, Misu T, Prayoonwiwat N, Berger T, Saiz A, Kim HJ, Nomura K, Callegaro D, Fujihara K, Aoki M (2016) Myelin injury without astrocytopathy in neuroinflammatory disorders with MOG antibodies. J Neurol Neurosurg Psychiatry 87:1257-1259. https://doi. org/10.1136/jnnp-2015-312676

34. Kierdorf K, Masuda T, Jordao MJC, Prinz M (2019) Macrophages at CNS interfaces: ontogeny and function in health and disease. Nat Rev Neurosci 20:547-562. https://doi.org/10.1038/s41583-019-0201-x

35. Kinzel S, Lehmann-Horn K, Torke S, Hausler D, Winkler A, Stadelmann C, Payne N, Feldmann L, Saiz A, Reindl M, Lalive PH, Bernard CC, Brück W, Weber MS (2016) Myelin-reactive antibodies initiate T cell-mediated CNS autoimmune disease by opsonization of endogenous antigen. Acta Neuropathol 132:43-58. https://doi.org/10.1007/s00401-016-1559-8
36. Kuerten S, Lanz TV, Lingampalli N, Lahey LJ, Kleinschnitz C, Mäurer M, Schroeter M, Braune S, Ziemssen T, Ho PP, Robinson WH, Steinman L (2020) Autoantibodies against central nervous system antigens in a subset of B cell-dominant multiple sclerosis patients. Proc Natl Acad Sci 117:21512-21518. https://doi.org/10.1073/pnas.2011249117

37. Kyratsous NI, Bauer IJ, Zhang G, Pesic M, Bartholomaus I, Mues M, Fang P, Worner M, Everts S, Ellwart JW, Watt JM, Potter BVL, Hohlfeld R, Wekerle H, Kawakami N (2017) Visualizing context-dependent calcium signaling in encephalitogenic T cells in vivo by two-photon microscopy. Proc Natl Acad Sci U S A 114:E6381-e6389. https://doi.org/10.1073/pnas.17018 06114

38. Lancaster E, Dalmau J (2012) Neuronal autoantigens-pathogenesis, associated disorders and antibody testing. Nat Rev Neurol 8:380-390. https:// doi.org/10.1038/nrneurol.2012.99

39. Lennon VA, Kryzer TJ, Pittock SJ, Verkman AS, Hinson SR (2005) lgG marker of optic-spinal multiple sclerosis binds to the aquaporin-4 water channel. J Exp Med 202:473-477

40. Liang J, Kong Q (2012) alpha-Cleavage of cellular prion protein. Prion 6:453-460. https://doi.org/10.4161/pri.22511

41. Linington C, Bradl M, Lassmann H, Brunner C, Vass K (1988) Augmentation of demyelination in rat acute allergic encephalomyelitis by circulating mouse monoclonal antibodies directed against a myelin/oligodendrocyte glycoprotein. Am J Pathol 130:443-454

42. Lodygin D, Hermann M, Schweingruber N, Flugel-Koch C, Watanabe T, Schlosser C, Merlini A, Korner H, Chang HF, Fischer HJ, Reichardt HM, Zagrebelsky M, Mollenhauer B, Kugler S, Fitzner D, Frahm J, Stadelmann C, Haberl M, Odoardi F, Flügel A (2019) beta-Synuclein-reactive T cells induce autoimmune CNS grey matter degeneration. Nature 566:503-508. https://doi.org/10.1038/s41586-019-0964-2

43. Lutterotti A, Yousef S, Sputtek A, Sturner KH, Stellmann JP, Breiden P, Reinhardt S, Schulze C, Bester M, Heesen C, Schippling S, Miller SD, Sospedra M, Martin R (2013) Antigen-specific tolerance by autologous myelin peptide-coupled cells: a phase 1 trial in multiple sclerosis. Sci Transl Med 5:188ra175. https://doi.org/10.1126/scitranslmed.3006168

44. Mader S, Kümpfel T, Meinl E (2020) Novel insights into pathophysiology and therapeutic possibilities reveal further differences between AQP4IgG- and MOG-lgG-associated diseases. Curr Opin Neurol 33:362-371. https://doi.org/10.1097/wco.0000000000000813

45. Mayer MC, Breithaupt C, Reindl M, Schanda K, Rostasy K, Berger T, Dale RC, Brilot F, Olsson T, Jenne D, Pröbstel AK, Dornmair K, Wekerle H, Hohlfeld R, Banwell B, Bar-Or A, Meinl E (2013) Distinction and temporal stability of conformational epitopes on myelin oligodendrocyte glycoprotein recognized by patients with different inflammatory central nervous system diseases. J Immunol 191:3594-3604. https://doi.org/10.4049/jimmu nol.1301296

46. McLaughlin KA, Chitnis T, Newcombe J, Franz B, Kennedy J, McArdel S, Kuhle J, Kappos L, Rostasy K, Pohl D, Gagne D, Ness JM, Tenembaum S, O'Connor KC, Viglietta V, Wong SJ, Tavakoli NP, de Seze J, Idrissova Z, Khoury SJ, Bar-Or A, Hafler DA, Banwell B, Wucherpfennig KW (2009) Agedependent $B$ cell autoimmunity to a myelin surface antigen in pediatric multiple sclerosis. J Immunol (Baltimore, Md: 1950) 183:4067-4076

47. Meyne F, Gloeckner SF, Ciesielczyk B, Heinemann U, Krasnianski A, Meissner B, Zerr I (2009) Total prion protein levels in the cerebrospinal fluid are reduced in patients with various neurological disorders. J Alzheimers Dis 17:863-873. https://doi.org/10.3233/JAD-2009-1110

48. Mikol DD, Stefansson K (1988) A phosphatidylinositol-linked peanut agglutinin-binding glycoprotein in central nervous system myelin and on oligodendrocytes. I Cell Biol 106:1273-1279

49. Misu T, Höftberger R, Fujihara K, Wimmer I, Takai Y, Nishiyama S, Nakashima I, Konno H, Bradl M, Garzuly F, Itoyama Y, Aoki M, Lassmann H (2013) Presence of six different lesion types suggests diverse mechanisms of tissue injury in neuromyelitis optica. Acta Neuropathol 125:815-827. https://doi.org/10.1007/s00401-013-1116-7

50. Moon HW, Hur M (2013) Interferon-gamma release assays for the diagnosis of latent tuberculosis infection: an updated review. Ann Clin Lab Sci 43:221-229

51. Mundt S, Greter M, Flügel A, Becher B (2019) The CNS immune landscape from the viewpoint of a T cell. Trends Neurosci 42:667-679. https://doi. org/10.1016/j.tins.2019.07.008

52. Nylander A, Hafler DA (2012) Multiple sclerosis. J Clin Investig 122:11801188. https://doi.org/10.1172/jci58649 
53. O'Connor KC, McLaughlin KA, De Jager PL, Chitnis T, Bettelli E, Xu C, Robinson WH, Cherry SV, Bar-Or A, Banwell B, Fukaura H, Fukazawa T, Tenembaum S, Wong SJ, Tavakoli NP, Idrissova Z, Viglietta V, Rostasy K, Pohl D, Dale RC, Freedman M, Steinman L, Buckle GJ, Kuchroo VK, Hafler DA, Wucherpfennig KW (2007) Self-antigen tetramers discriminate between myelin autoantibodies to native or denatured protein. Nat Med 13:211-217

54. Ogawa R, Nakashima I, Takahashi T, Kaneko K, Akaishi T, Takai Y, Sato DK, Nishiyama S, Misu T, Kuroda H, Aoki M, Fujihara K (2017) MOG antibodypositive, benign, unilateral, cerebral cortical encephalitis with epilepsy. Neurol Neuroimmunol Neuroinflamm 4:e322. https://doi.org/10.1212/ nxi.0000000000000322

55. Perera NC, Wiesmuller KH, Larsen MT, Schacher B, Eickholz P, Borregaard N, Jenne DE (2013) NSP4 is stored in azurophil granules and released by activated neutrophils as active endoprotease with restricted specificity. J Immunol (Baltimore, Md : 1950) 191:2700-2707. https://doi.org/10.4049/ jimmunol.1301293

56. Piddlesden SJ, Lassmann H, Zimprich F, Morgan BP, Linington C (1993) The demyelinating potential of antibodies to myelin oligodendrocyte glycoprotein is related to their ability to fix complement. Am J Pathol 143:555-564

57. Pinna D, Corti D, Jarrossay D, Sallusto F, Lanzavecchia A (2009) Clonal dissection of the human memory B-cell repertoire following infection and vaccination. Eur J Immunol 39:1260-1270. https://doi.org/10.1002/ eji.200839129

58. Planas R, Santos R, Tomas-Ojer P, Cruciani C, Lutterotti A, Faigle W, Schaeren-Wiemers N, Espejo C, Eixarch H, Pinilla C, Martin R, Sospedra M (2018) GDP-I-fucose synthase is a CD4(+)T cell-specific autoantigen in DRB3*02:02 patients with multiple sclerosis. Sci Transl Med 10:eaat4301. https://doi.org/10.1126/scitranslmed.aat4301

59. Ramanathan S, Reddel SW, Henderson A, Parratt JD, Barnett M, Gatt PN, Merheb V, Kumaran RY, Pathmanandavel K, Sinmaz N, Ghadiri M, Yiannikas C, Vucic S, Stewart G, Bleasel AF, Booth D, Fung VS, Dale RC, Brilot $F$ (2014) Antibodies to myelin oligodendrocyte glycoprotein in bilateral and recurrent optic neuritis. Neurol Neuroimmunol Neuroinflamm 1:e40. https://doi.org/10.1212/nxi.0000000000000040

60. Reindl M, Waters P (2018) Myelin oligodendrocyte glycoprotein antibodies in neurological disease. Nat Rev Neurol 15:89-102. https://doi. org/10.1038/s41582-018-0112-x

61. Sabatino JJ Jr, Pröbstel AK, Zamvil SS (2019) B cells in autoimmune and neurodegenerative central nervous system diseases. Nat Rev Neurosci 20:728-745. https://doi.org/10.1038/s41583-019-0233-2

62. Sabatino JJ Jr, Wilson MR, Calabresi PA, Hauser SL, Schneck JP, Zamvil SS (2019) Anti-CD20 therapy depletes activated myelin-specific CD8(+) T cells in multiple sclerosis. Proc Natl Acad Sci U S A 116:25800-25807. https://doi.org/10.1073/pnas.1915309116

63. Sharma R, Fischer MT, Bauer J, Felts PA, Smith KJ, Misu T, Fujihara K, Bradl M, Lassmann H (2010) Inflammation induced by innate immunity in the central nervous system leads to primary astrocyte dysfunction followed by demyelination. Acta Neuropathol 120:223-236. https://doi. org/10.1007/s00401-010-0704-z

64. Soltys J, Liu Y, Ritchie A, Wemlinger S, Schaller K, Schumann H, Owens GP, Bennett JL (2019) Membrane assembly of aquaporin-4 autoantibodies regulates classical complement activation in neuromyelitis optica. J Clin Invest 129:2000-2013. https://doi.org/10.1172/jci122942

65. Spadaro M, Gerdes LA, Krumbholz M, Ertl-Wagner B, Thaler FS, Schuh E, Metz I, Blaschek A, Dick A, Brück W, Hohlfeld R, Meinl E, Kümpfel T (2016) Autoantibodies to MOG in a distinct subgroup of adult multiple sclerosis. Neurol Neuroimmunol Neuroinflamm 3:e257. https://doi.org/10.1212/ nxi.0000000000000257

66. Spadaro M, Winklmeier S, Beltran E, Macrini C, Höftberger R, Schuh E, Thaler FS, Gerdes LA, Laurent S, Gerhards R, Brändle S, Dornmair K, Breithaupt C, Krumbholz M, Moser M, Krishnamoorthy G, Kamp F, Jenne D, Hohlfeld R, Kümpfel T, Lassmann H, Kawakami N, Meinl E (2018) Pathogenicity of human antibodies against myelin oligodendrocyte glycoprotein. Ann Neurol 84:315-328. https://doi.org/10.1002/ana.25291

67. Stangel M, Fredrikson S, Meinl E, Petzold A, Stuve O, Tumani H (2013) The utility of cerebrospinal fluid analysis in patients with multiple sclerosis. Nat Rev Neurol 9:267-276. https://doi.org/10.1038/nrneurol.2013.41
68. Steinman L (2014) Immunology of relapse and remission in multiple sclerosis. Annu Rev Immunol 32:257-281. https://doi.org/10.1146/annur ev-immunol-032713-120227

69. Steinman L, Ho PP, Robinson WH, Utz PJ, Villoslada P (2019) Antigenspecific tolerance to self-antigens in protein replacement therapy, gene therapy and autoimmunity. Curr Opin Immunol 61:46-53. https://doi. org/10.1016/j.coi.2019.07.011

70. Tengvall K, Huang J, Hellstrom C, Kammer P, Bistrom M, Ayoglu B, Lima Bomfim I, Stridh P, Butt J, Brenner N, Michel A, Lundberg K, Padyukov L, Lundberg IE, Svenungsson E, Ernberg I, Olafsson S, Dilthey AT, Hillert J, Alfredsson L, Sundstrom P, Nilsson P, Waterboer T, Olsson T, Kockum I (2019) Molecular mimicry between Anoctamin 2 and Epstein-Barr virus nuclear antigen 1 associates with multiple sclerosis risk. Proc Natl Acad Sci U S A 116:16955-16960. https://doi.org/10.1073/pnas.1902623116

71. Thaler FS, Thaller AL, Biljecki M, Schuh E, WinkImeier S, Mahler CF, Gerhards R, Volk S, Schnorfeil F, Subklewe M, Hohlfeld R, Kümpfel T, Meinl E (2019) Abundant glutamic acid decarboxylase (GAD)-reactive B cells in gad-antibody-associated neurological disorders. Ann Neurol 85:448-454. https://doi.org/10.1002/ana.25414

72. Tushaus J, Muller SA, Kataka ES, Zaucha J, SebastianMonasor L, Su M, Guner G, Jocher G, Tahirovic S, Frishman D, Simons M, Lichtenthaler SF (2020) An optimized quantitative proteomics method establishes the cell type-resolved mouse brain secretome. EMBO J. https://doi.org/10.15252/ embj.2020105693

73. Vallabh SM, Nobuhara CK, Llorens F, Zerr I, Parchi P, Capellari S, Kuhn E, Klickstein J, Safar JG, Nery FC, Swoboda KJ, Geschwind MD, Zetterberg H, Arnold SE, Minikel EV, Schreiber SL (2019) Prion protein quantification in human cerebrospinal fluid as a tool for prion disease drug development. Proc Natl Acad Sci U S A 116:7793-7798. https://doi.org/10.1073/ pnas. 1901947116

74. van Sonderen $\mathrm{A}$, Arino $\mathrm{H}$, Petit-Pedrol M, Leypoldt F, Kortvelyessy $\mathrm{P}$, Wandinger KP, Lancaster E, Wirtz PW, Schreurs MW, Sillevis Smitt PA, Graus F, Dalmau J, Titulaer MJ (2016) The clinical spectrum of Caspr2 antibodyassociated disease. Neurology 87:521-528. https://doi.org/10.1212/ wnl.0000000000002917

75. Vidarsson G, Dekkers G, Rispens T (2014) IgG subclasses and allotypes: from structure to effector functions. Front Immunol 5:520. https://doi. org/10.3389/fimmu.2014.00520

76. Wang KC, Koprivica V, Kim JA, Sivasankaran R, Guo Y, Neve RL, He Z (2002) Oligodendrocyte-myelin glycoprotein is a Nogo receptor ligand that inhibits neurite outgrowth. Nature 417:941-944. https://doi.org/10.1038/ nature00867

77. Watkins TA, Emery B, Mulinyawe S, Barres BA (2008) Distinct stages of myelination regulated by gamma-secretase and astrocytes in a rapidly myelinating CNS coculture system. Neuron 60:555-569. https://doi. org/10.1016/..neuron.2008.09.011

78. Weider M, Starost L, Groll K, Kuspert M, Sock E, Wedel M, Frob F, Schmitt C, Baroti T, Hartwig AC, Hillgartner S, Piefke S, Fadler T, Ehrlich M, Ehlert C, Stehling M, Albrecht S, Jabali A, Scholer HR, Winkler J, Kuhlmann T, Wegner M (2018) Nfat/calcineurin signaling promotes oligodendrocyte differentiation and myelination by transcription factor network tuning. Nat Commun 9:899. https://doi.org/10.1038/s41467-018-03336-3

79. Winklmeier S, Schlüter M, Spadaro M, Thaler FS, Vural A, Gerhards R, Macrini C, Mader S, Kurne A, Inan B, Karabudak R, Ozbay FG, Esendagli G, Hohlfeld R, Kümpfel T, Meinl E (2019) Identification of circulating MOGspecific B cells in patients with MOG antibodies. Neurol Neuroimmunol Neuroinflamm 6:625. https://doi.org/10.1212/nxi.0000000000000625

80. Wisniewski JR, Zougman A, Nagaraj N, Mann M (2009) Universal sample preparation method for proteome analysis. Nat Methods 6:359-362. https://doi.org/10.1038/nmeth.1322

81. Zamvil SS, Slavin AJ (2015) Does MOG Ig-positive AQP4-seronegative opticospinal inflammatory disease justify a diagnosis of NMO spectrum disorder. Neurol Neuroimmunol Neuroinflamm 2:62. https://doi. org/10.1212/nxi.0000000000000062

\section{Publisher's Note}

Springer Nature remains neutral with regard to jurisdictional claims in published maps and institutional affiliations. 